\title{
Multi-Organization - Multi-Discipline Effort Developing a Mitigation Concept for Planetary Defense
}

\author{
Ronald Y. Leung, Brent W. Barbee, \\ Bernard D. Seery, Myra Bambacus \\ NASA-Goddard Space Flight Center \\ 8800 Greenbelt Road, \\ Greenbelt, MD 20771 \\ 202-656-2077 \\ Ronald.Y.Leung@.nasa.gov \\ David S. P. Dearborn, Paul L. Miller \\ Lawrence Livermore National Laboratory \\ 7000 East Avenue / P.O, Box 808 \\ Livermore, CA 94550 \\ 925-422-7219 \\ dearborn2@llnl.gov
}

Abstract-There have been significant recent efforts in addressing mitigation approaches to neutralize Potentially Hazardous Asteroids (PHA). One such research effort was performed in 2015 by an integrated, inter-disciplinary team of asteroid scientists, energy deposition modeling scientists, payload engineers, orbital dynamicist engineers, spacecraft discipline engineers, and systems / architecture engineers from NASA's Goddard Space Flight Center (GSFC) and the Department of Energy (DoE) / National Nuclear Security Administration (NNSA) laboratories (Los Alamos National Laboratory (LANL), Lawrence Livermore National Laboratories (LLNL) and Sandia National Laboratories). The study team collaborated with GSFC's Integrated Design Center's Mission Design Lab (MDL) which engaged a team of GSFC flight hardware discipline engineers to work with GSFC, LANL, and LLNL Near-Earth Asteroid (NEA)-related subject matter experts during a one-week intensive concept formulation study in an integrated concurrent engineering environment. This team has analyzed the first of several distinct study cases for a multi-year NASA research grant. This Case 1 study references the NEA named Bennu as the notional target due to the availability of a very detailed Design Reference Asteroid (DRA) model for its orbit and physical characteristics (courtesy of the Origins, Spectral Interpretation, Resource Identification, Security-Regolith Explorer [OSIRIS-REx] mission team). The research involved the formulation and optimization of spacecraft trajectories to intercept Bennu, overall mission and architecture concepts, and high-fidelity modeling of both kinetic impact (spacecraft collision to change a NEA's momentum and orbit) and nuclear detonation effects on Bennu, for purposes of deflecting Bennu.

TABLE OF CONTENTS

1. INTRODUCTION 1

2. CONCEPT FORMULATION CONSTRAINTS AND

DRIVERS. .2

3. TOP LEVEL MitigATION FUNCTIONS (POST DETECTION). 3

4. MISSION TIMELINE ...................................................... 4 5. AUTONOMOUS NAVIGATION SYSTEM .................... 4 6. ORBITAL PHYSICS ..........................................................5 5 7. FUNCTIONAL CONCEPT.............................................6 6
Lee Finewood, Kevin C. Greenaugh, Anthony Lewis National Nuclear Security Administration Dept. of Energy / Forrestal Building 1000 Independence Ave. SW Washington, DC 20585 202-287-6584 lee.finewood@nnsa.doe.gov

Robert P. Weaver, Catherine Plesko Los Alamos National Laboratory MS T087 / PO Box 1663

Los Alamos NM 87545 505-667-4756 rpw@lanl.gov

8. FunCtional Allocation for CASE 1 ............... 7

9. A LTERNATIVE LAUNCH VEHICLES........................8 10. NOTIONAL SPACE SEGMENT DEVELOPMENT AND DEPLOYMENT TIMELINE (1 ${ }^{\text {ST }}$ ARTICLE ONLY) 10 11. MISSION EFFECTIVENESS / MISSION SUCCESS 10 12. CONCEPT OF CAMPAIGN MODE...........................11 13. TEAM FINDINGS ..........................................12

14. SUMMARY ........................................................17

ACKNOWLEDGEMENTS ........................................18

REFERENCES ......................................................... 18

BIOGRAPHY ..............................................................19

\section{INTRODUCTION}

This paper is intended to be one of a set of papers to be produced by an integrated study team comprised of NASA/ GSFC, DoE/NNSA LANL, and LLNL, of work conducted in the October 2015 timeframe. We refer to results of a parallel paper on the uncertainty caused by physical properties of asteroids and how they respond to a deflection impulse.

The focus of this paper is on the Delivery Segment and Space Segment portions of a larger NEA Mitigation Architecture as depicted in Figure 1. This activity produced a detailed concept of a multi-purpose spacecraft to carry out planetary defense mission objectives. While the Bennu scenario was utilized as a point of departure for analysis purposes, the spacecraft concept is intended to be applicable to a broader range of possible hazardous NEA scenarios. The MDL systems concept development study objectives included formulating a spacecraft concept capable of intercepting an NEA, functioning as either a Kinetic Impactor (KI) or a Nuclear Energy Device (NED) delivery system. The assumed target for this study is the Potentially Hazardous [to Earth] Asteroid (PHA) known as 101955 Bennu (1999 RQ36), which is the destination for NASA's OSIRIS-REx asteroid sample return mission (launched in September 2016). ${ }^{[1]}$ 


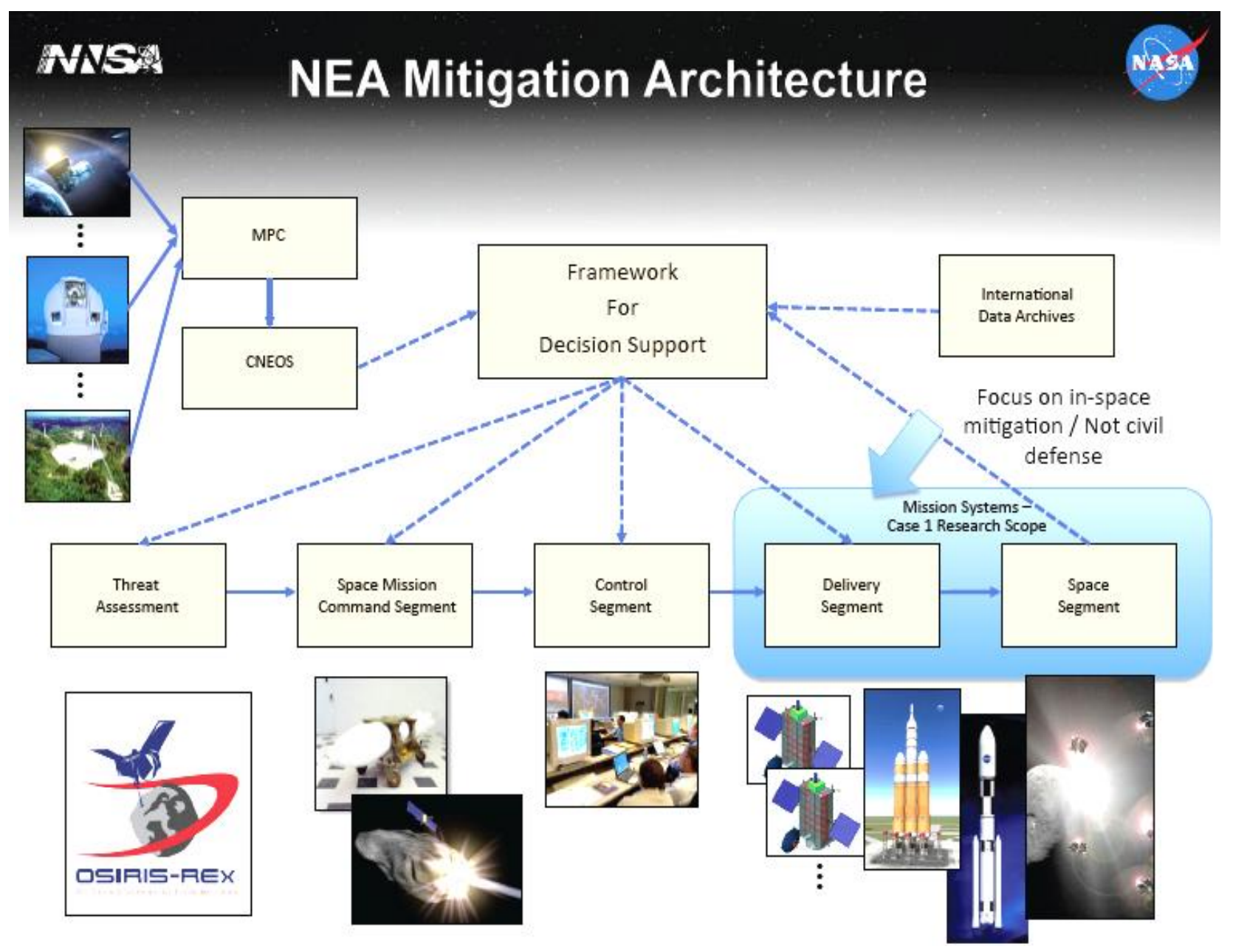

Figure 1. NEA Mitigation Architecture

The spacecraft's performance as a KI was modeled in the MDL, with the goal that it also could function as a NED delivery system (with the NED installed in the spacecraft). Accordingly, the spacecraft would be capable of housing the NED and transporting it to the targeted NEA with the goal of little or no changes to the spacecraft. Thus, the resulting higher-level objective for the MDL study was to develop a concept for a multi-functional spacecraft (operating alone or as part of a campaign including multiple spacecraft), deliverable to a target NEA by a variety of current and planned US launch vehicles or other launch delivery systems. ${ }^{[2]}$

The spacecraft concept and corresponding mission profile developed during the MDL study was named HAMMER (Hypervelocity Asteroid Mitigation Mission for Emergency Response).

\section{CONCEPT Formulation CONSTRAints AND DRIVERS}

Class A missions are extremely critical operational systems where all practical measures are taken to ensure mission success. They have the highest cost, are of high complexity, and the longest mission life with tight launch constraints. Contract types for these systems are typically cost plus because of the substantial development risk and resultant oversight activities. These missions are achieved by strict implementation of mission assurance processes derived through proven best practices to achieve mission success over the desired life of the system. All practical measures, to include full incorporation of all specifications/standards contract requirements with little to no tailoring, are taken to achieve mission success for such missions. Class A missions are long life, (nominally greater than 5 years) and represent large national investments for critical applications. ${ }^{[3]}$

NASA Class A missions are represented by flagship missions such as the Hubble Space Telescope, Cassini, and the Jupiter Icy Moon Orbiter (JIMO). National Security Space (NSS) Class A missions include the Global Positioning System satellite and military communication satellite systems to include Milstar. ${ }^{[4]}$

Additionally, the selection of the largest commercially available launch vehicle was included as part of the mission objectives, as shown in Table 1. 
Table 1. Case Study 1 Summary of Mission Objectives and Mission Goals / Requirements

\begin{tabular}{|c|c|c|}
\hline Mission Objectives & Mission Goals / Requirements & Comments \\
\hline $\begin{array}{l}\text { Track, intercept, divert a PHA using a KI } \\
\text { as the first option if viable }\end{array}$ & $\begin{array}{l}\text { Deliver as much mass as possible, } \\
\text { imparting max KE, at closing velocity } \\
\text { up to } 10 \mathrm{~km} / \mathrm{s}\end{array}$ & $\begin{array}{l}\text { May challenge spacecraft control } \\
\text { authority }\end{array}$ \\
\hline $\begin{array}{l}\text { Utilize largest commercially available US } \\
\text { launch vehicle }\end{array}$ & Absolute navigation to $\pm 5 \mathrm{~km}$ & \\
\hline $\begin{array}{l}\text { Consider use of depleted U238 density } \\
19.1 \mathrm{gm} / \mathrm{cm} 3 \text {, in order to use full } \\
\text { capability (GLOW [Gross Liftoff } \\
\text { Weight]) of the Delta IV heavy class } \\
\text { launch vehicle of } \sim 8870 \mathrm{~kg} \text { payload }\end{array}$ & Transition to relative nav $\sim$ I- 1 day & $\begin{array}{l}\text { Overall response time due to round trip } \\
\text { time delay becomes a limiting factor }\end{array}$ \\
\hline Maintain Operational readiness & $\begin{array}{l}\text { Maintain guidance until impact with } \\
\text { max telemetry }\end{array}$ & $\begin{array}{l}\text { Overall mission duration as well as } \\
\text { mission lead time becomes a limiting } \\
\text { factor }\end{array}$ \\
\hline Robust and resilient architecture & $\begin{array}{l}\text { Provide diagnostic telemetry for off- } \\
\text { nominal events }\end{array}$ & \\
\hline Class A+ reliability for deployed system & $\begin{array}{l}\text { Fail operational during mission critical } \\
\text { phases }\end{array}$ & $\begin{array}{l}\text { Overall mitigation FOM (figure of } \\
\text { merit) needs consideration }\end{array}$ \\
\hline $\begin{array}{l}\text { Ready accommodation of KI or NED } \\
\text { payload }\end{array}$ & Fail safe during non-critical phases & \\
\hline $\begin{array}{l}\text { Max Range: } 2.4 \text { AU from Earth; } 1.4 \mathrm{AU} \\
\text { from Sun }\end{array}$ & & \\
\hline
\end{tabular}

\section{Top LeVEl Mitigation FunCtions (Post Detection)}

The major functional elements required for the timely mitigation of PHA employ a feedback loop control system. Once the object has been detected on a hazardous course with our planet then actionable object information will be needed both in sufficient detail and in a timely manner in order for a control system to effect the appropriate mitigation action(s). This control system will utilize the necessary in place segments previously depicted as part of the NEA Mitigation Architecture to include a ground segment, launch segment, space segment, and communications segment. For simplification purposes, only the key segments are depicted in Figure 2. There are a number of characteristics which become drivers for this particular control loop: a) the total round trip delay / propagation time of the communications segment (ranging from 1 to possible $3 \mathrm{AU}$ ); b) the availability (including any delays such as the quantity and availability) of the groundbased delivery system; c) the end-to-end control loop processing time (or loop response time).

This system is likely to include potential manufacturing, launch vehicles, launch processing, spacecraft, mitigation payloads (to be paired with spacecraft), spacecraft command and communications systems, payload command and communications systems, as well as PHA detection, tracking, navigation and guidance functions. As shown, all of these functions and elements will need to work in coordination with each other in a timely, reliable, and robust manner.

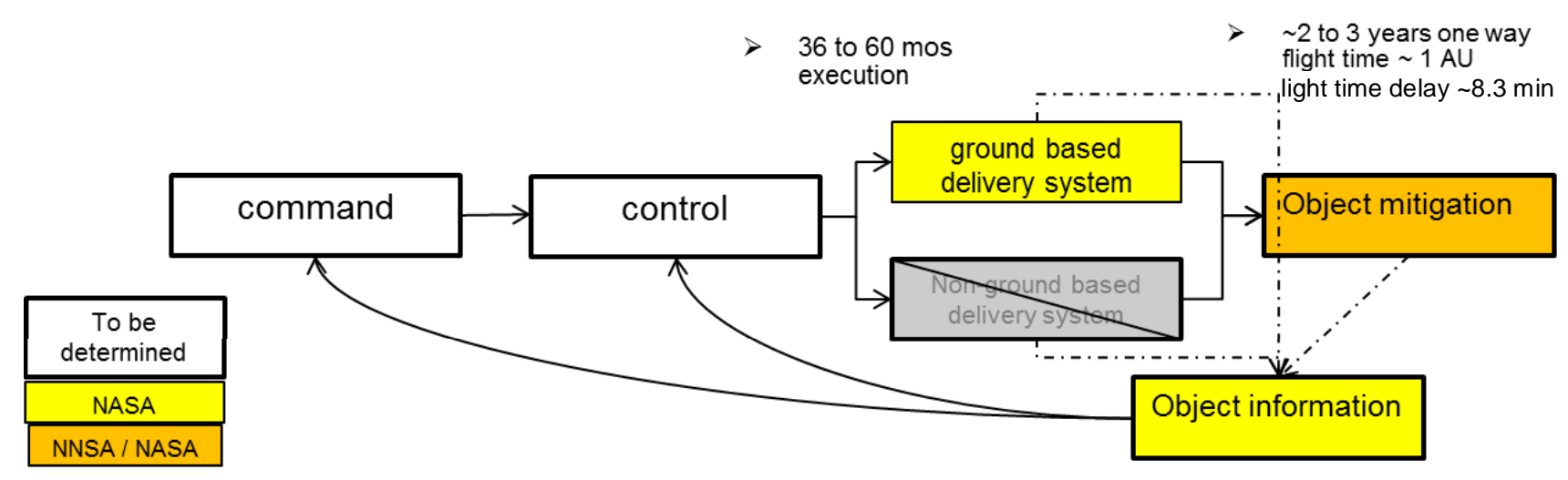

Figure 2. PHA Mitigation Control Loop Concept ${ }^{[5]}$ 


\section{Mission Timeline}

The reference timeline, see Figure 3, is a launch on January 1, 2023, with a 1-week on orbit check-out and an expected cruise phase of 740 days. The mitigation / encounter or impact phase commences roughly one day before the January 10, 2025 impact (I). Autonomous operations begin at that point. Target acquisition engages at around 9,000 kilometers from the encounter point with on-board targeting acquisition strategies such as infrared or mass centroid detection. At I-1 hour (around 36,000 kilometers) commit target processing and on-board optical imaging commences; at I-10 minutes (approximately 6,000 kilometers from engagement) velocity is approximately $4.48 \mathrm{~km} / \mathrm{s}$ with formulation concept upper bound goal established at 10 $\mathrm{km} / \mathrm{s}$.

\section{Autonomous Navigation System}

Prior to the terminal navigation timeline phase the autonomous navigation system (ANS) is in update mode with ground segment systems. It is then corrected and refreshed with information to allow autonomous navigation to take place on board within spacecraft avionics. This function guides and navigates the spacecraft in the final terminal impact sequence towards the asteroid. Figure 3 shows the closed-loop functional block diagram of this ANS process.

Figure 4 depicts the ANS subsystem of the terminal approach phase beginning at impact minus 2 hours (I-120 minutes). It depicts the linear covariance analysis, the Monte Carlo error analysis, and utilizes a sequential Kalman filter with observations derived from the asteroid centroid location sensor. It solves for the initial position and velocity of the spacecraft with respect to the target asteroid.

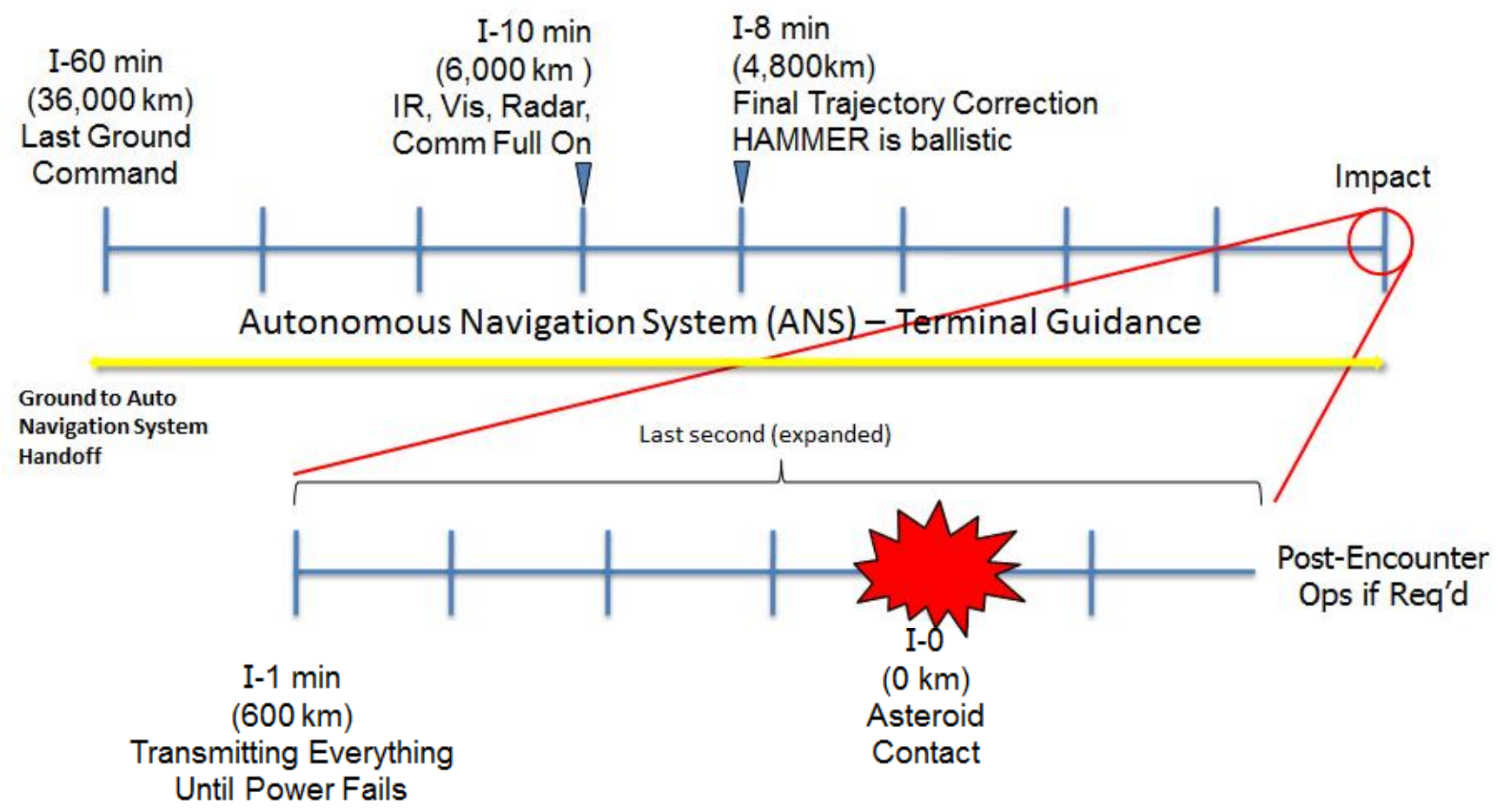

Figure 3. Case 1 Study Mission and Expanded Impact Timelines 


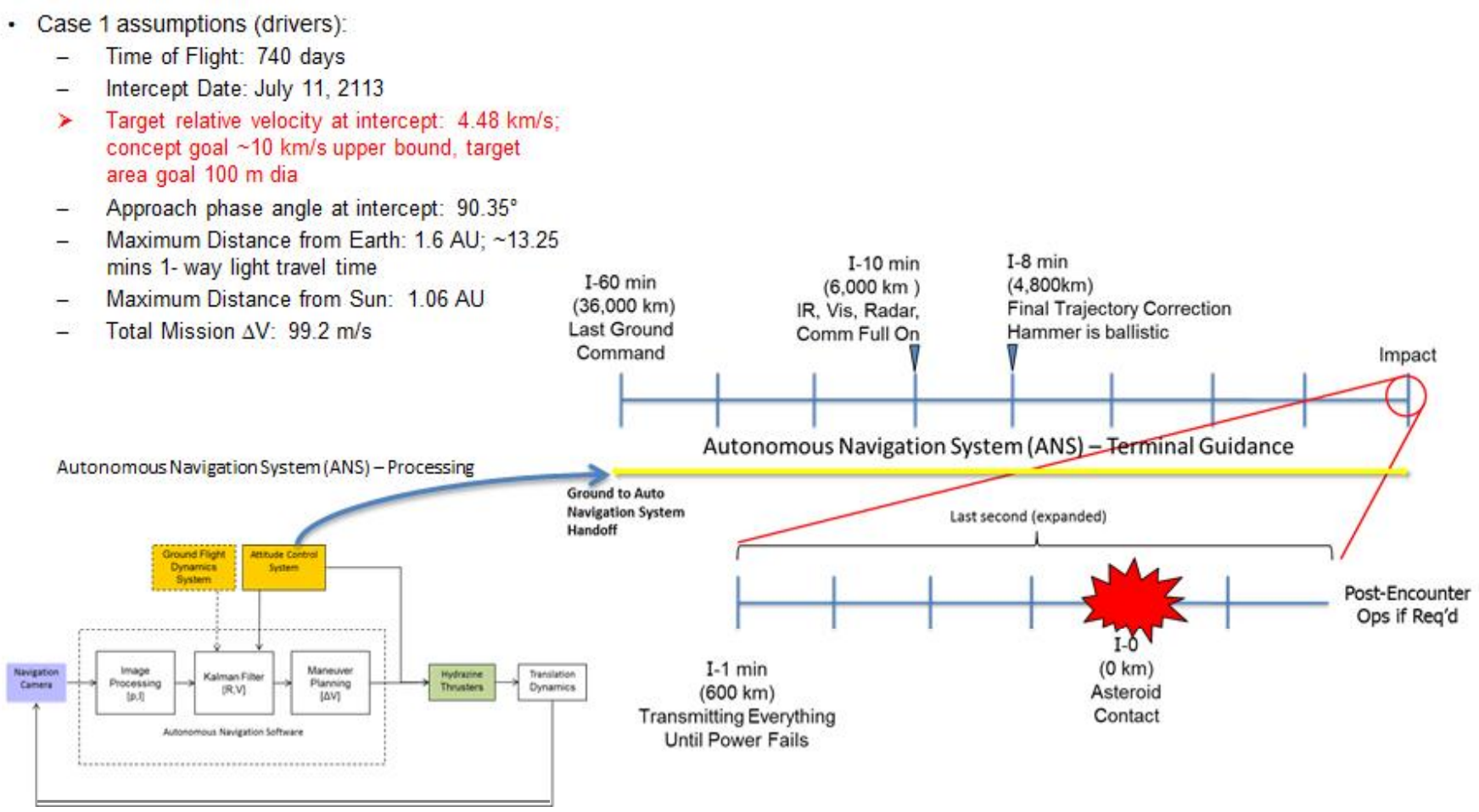

Figure 4. Autonomous Navigation Processing Subsystem

\section{Orbital Physics}

The next three figures (Figures 5,6 and 7) depict the heliocentric orbit trajectories for the departure, arrival, and final encounter terminal phases. These trajectories determine the environments in which the spacecraft and payload must operate during the launch, transit, and terminal mitigation encounter phases with the asteroid.

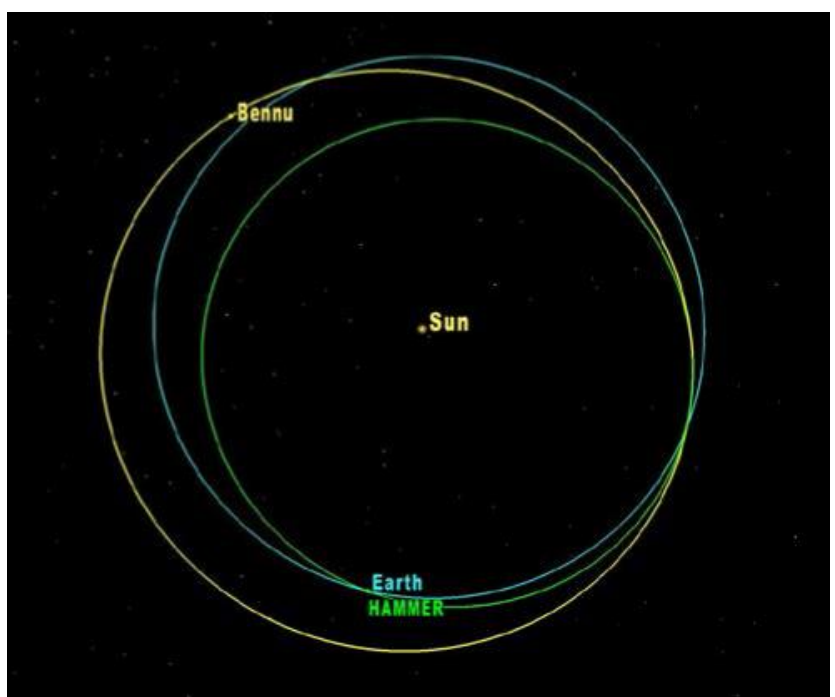

Figure 5. Heliocentric Trajectory for the Earth Departure Phase

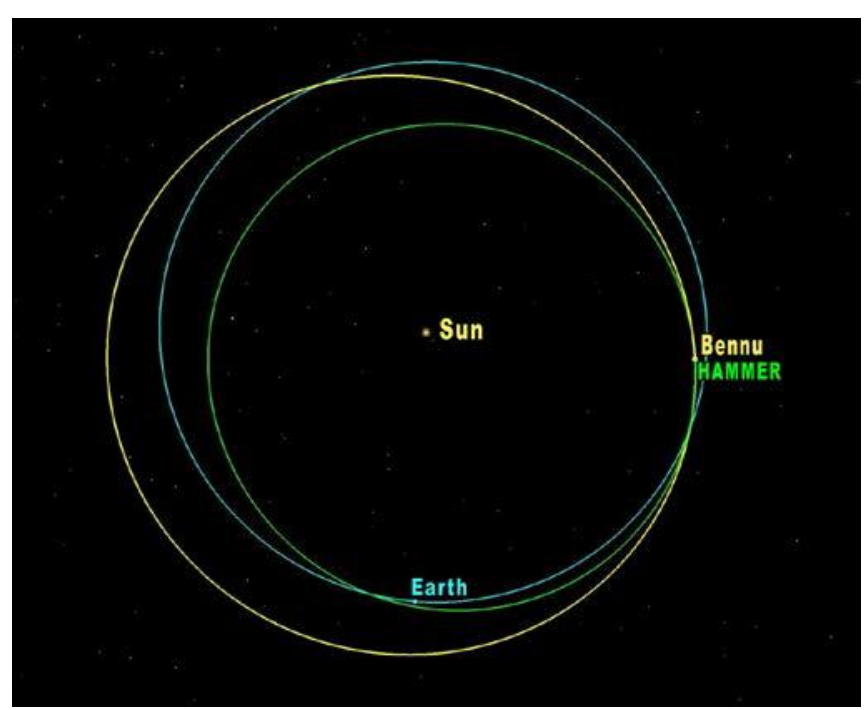

Figure 6. Heliocentric Trajectory for the Arrival Phase at 101995 Bennu

NOTE: In Figure 6, the asteroid is only in partial view with respect to the spacecraft in the foreground.

These three figures were all simulated using the orbit determination toolbox (ODTBX) software analysis which is an advanced navigation and mission simulation and analysis tool used for concept exploration, early concept formulation, and/or rapid design center formulation environments. This tool was developed by the Navigation and Mission Design Branch at the NASA GSFC. 


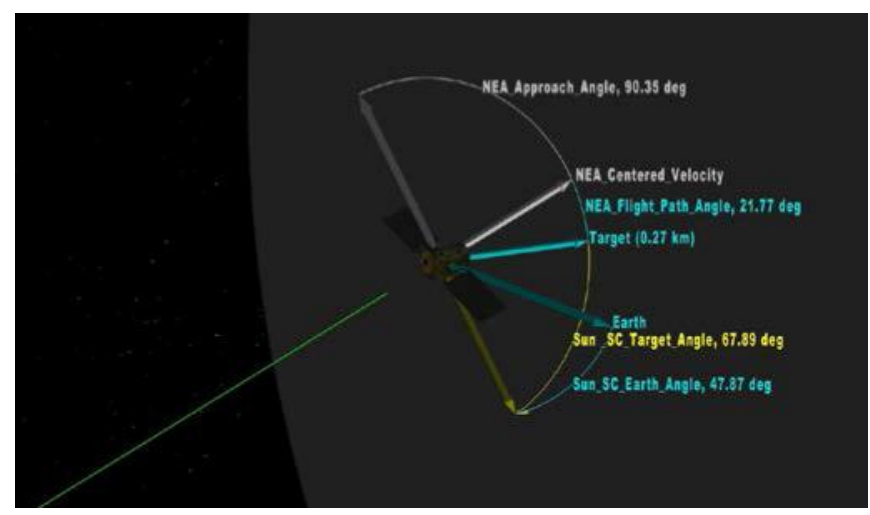

Figure 7. Final Approach Angles, Geometry and Spacecraft Orientation with the Target

\section{FunCtional CONCEPT}

As part of the formulation strategy, a functional concept diagram was utilized. This functional block diagram (Figure 8 ) was design approach agnostic. Salient top-level functions of HAMMER are depicted in this figure. The major elements were used as concept building blocks. Kinetic payloads were depicted in simpler forms and building blocks. Multiple or modular kinetic or NED, payloads along with partitioning strategies, were conveyed to the concept development team. The separation and simplification of payload to spacecraft interfaces were depicted. This allowed for the partitioning of functions and the trading of these functions between the various elements of payload blocks and spacecraft subsystems.

The top portion contains the kinetic payload which is in the conical section. The center cylindrical section contains simpler / traditional spacecraft avionics such as Attitude Control System (ACS), thermal control system, Command and Data Handling $(\mathrm{C} \& \mathrm{DH})$, secondary power, separation system and perhaps $8,000 \mathrm{~kg}$ of another mass slug. The bottom section contains more traditional spacecraft functions such as communications, ACS, C\&DH, thermal, propulsion, solar arrays, and power.

The goal was to achieve modular, separable, loosely coupled functional allocations of the payload and spacecraft precision delivery functions. Additionally, the two-part payload concept would allow for change out of one of these as possible NED or hybrid combination payload(s). It is noted that a number of functions are shown in each section. This is to depict both the function(s) potentially needed within each section as well as denoting future allocation trade-offs such as performance or redundancy needs. Spacecraft housekeeping and other delivery functions were to be grouped together to allow for both simpler payload to spacecraft interfaces and to facilitate partitioning of functions within HAMMER, as well as inter-organizational/ inter-agency roles and responsibilities. It is anticipated that this functional block diagram will remain a work in progress and will continue to evolve and further develop as additional studies are continued and cases / point-of-departure concepts are considered.

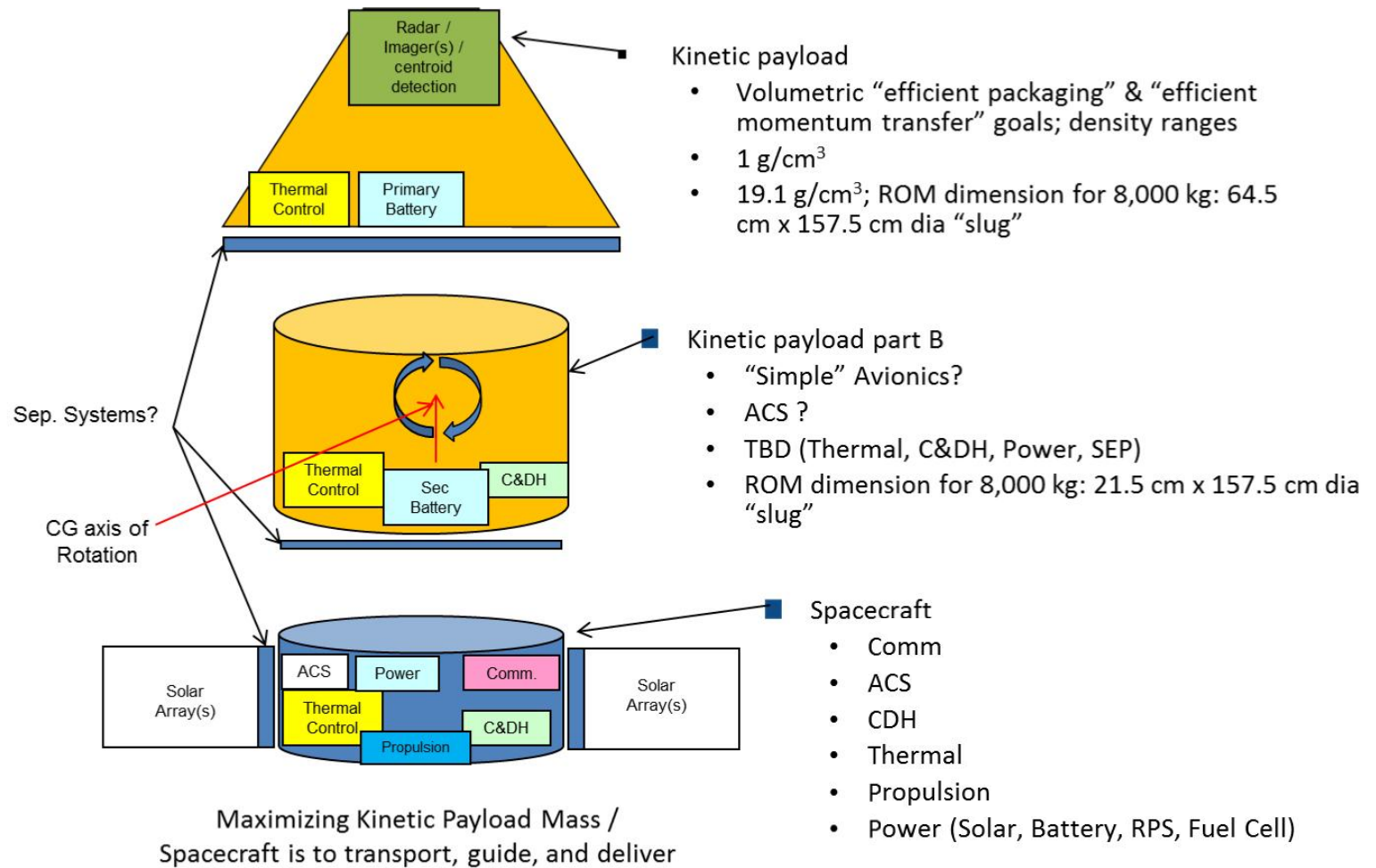

Figure 8. Modular Decomposition of HAMMER functions 


\section{Functional Allocation for Case 1}

Figure 9 depicts the current representation for the Case 1 allocation of spacecraft functions and payload functions. Within the spacecraft there is a telecommunications subsystem, an avionics subsystem, propulsion subsystem, power subsystem, thermal subsystem, attitude control system and a control and data handling subsystem. On the lower left is the interface to the NED or kinetic energy device. It's a simpler interface to this modular exchangeable payload. It is a concept goal that one-way data and power are the only necessary interfaces for this modular payload. This concept should allow for modular exchange and very late integration of this payload with the spacecraft. Internal to this payload, it is anticipated that the payload would have its own batteries, control electronics, detection (camera-like) function and target acquisition system, as well as some internal navigation detection systems.
Figure 10 depicts the notional spacecraft concept. It is a rectangular structure where the mechanical/structural loads are carried along its length and through the center of the spacecraft with a thrust tube down the center. The potential NEDs are along the sides. This allows deployment of the NEDs, if necessary. The attitude control thrusters are in the corners of the spacecraft along with a propulsion system ( $+\mathrm{X}$ axis) to allow release of the NEDs. The solar arrays and the single high-gain antenna are fully gimbaled. This is needed in order to maintain power from a distance of up to 1.4 AU from the Sun and communicate to Earth at a distance of up to $2.4 \mathrm{AU}$.

Figure 11 shows the spacecraft in the launch configuration within the Delta-IV Heavy. It occupies only about twothirds of the volume since the spacecraft mass is concentrated. The overall fairing size of the Delta-IV Heavy is shown to be about 9.8 meters in length, about 4.6 meters in diameter within the dynamic fairing envelope. The spacecraft is attached to a 3-meter fairing adapter. The overall spacecraft length is just over 5 meters.

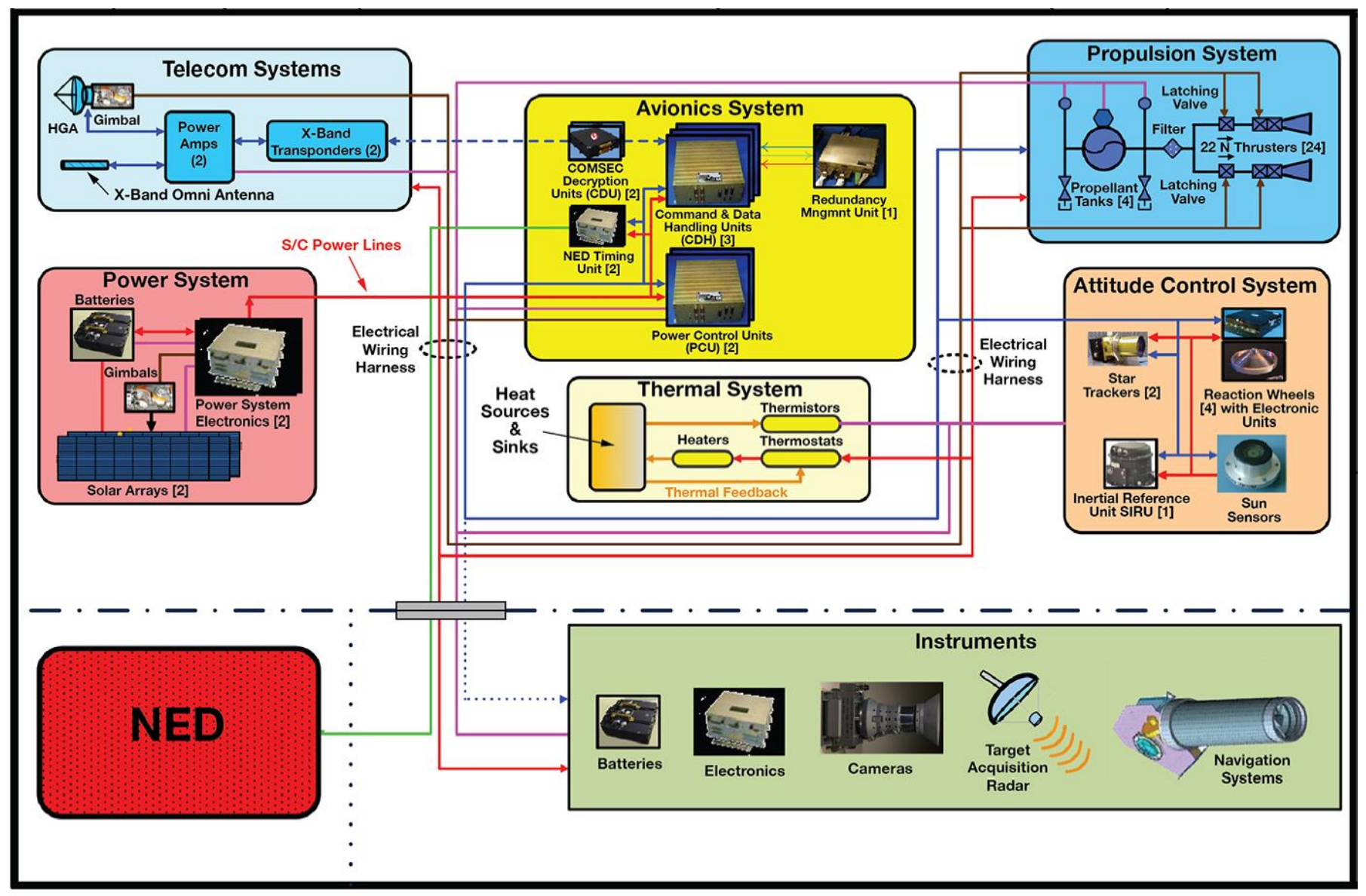

Figure 9. Spacecraft Subsystems Functional Block Diagram as Allocated for the Case 1 Study 


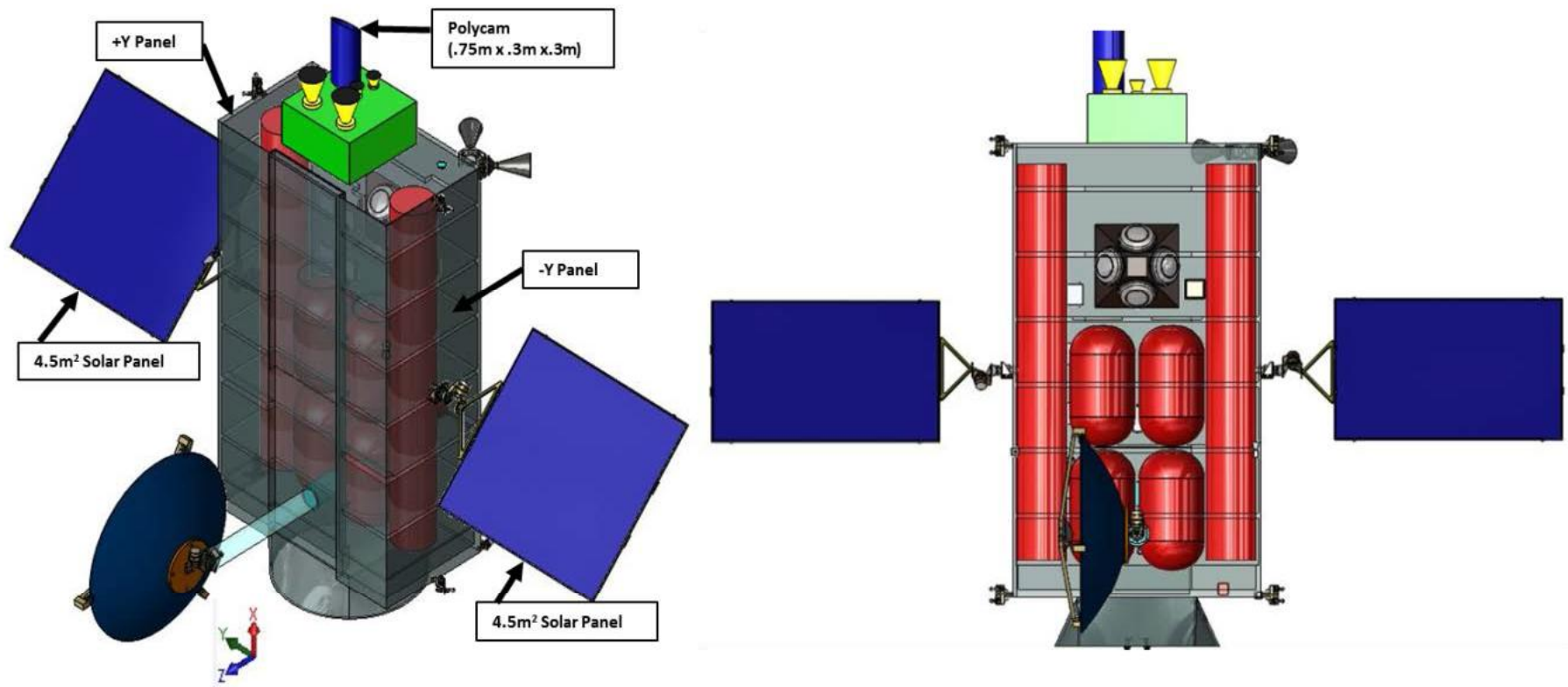

Figure 10. Case Study 1 Notional Point of Departure Spacecraft

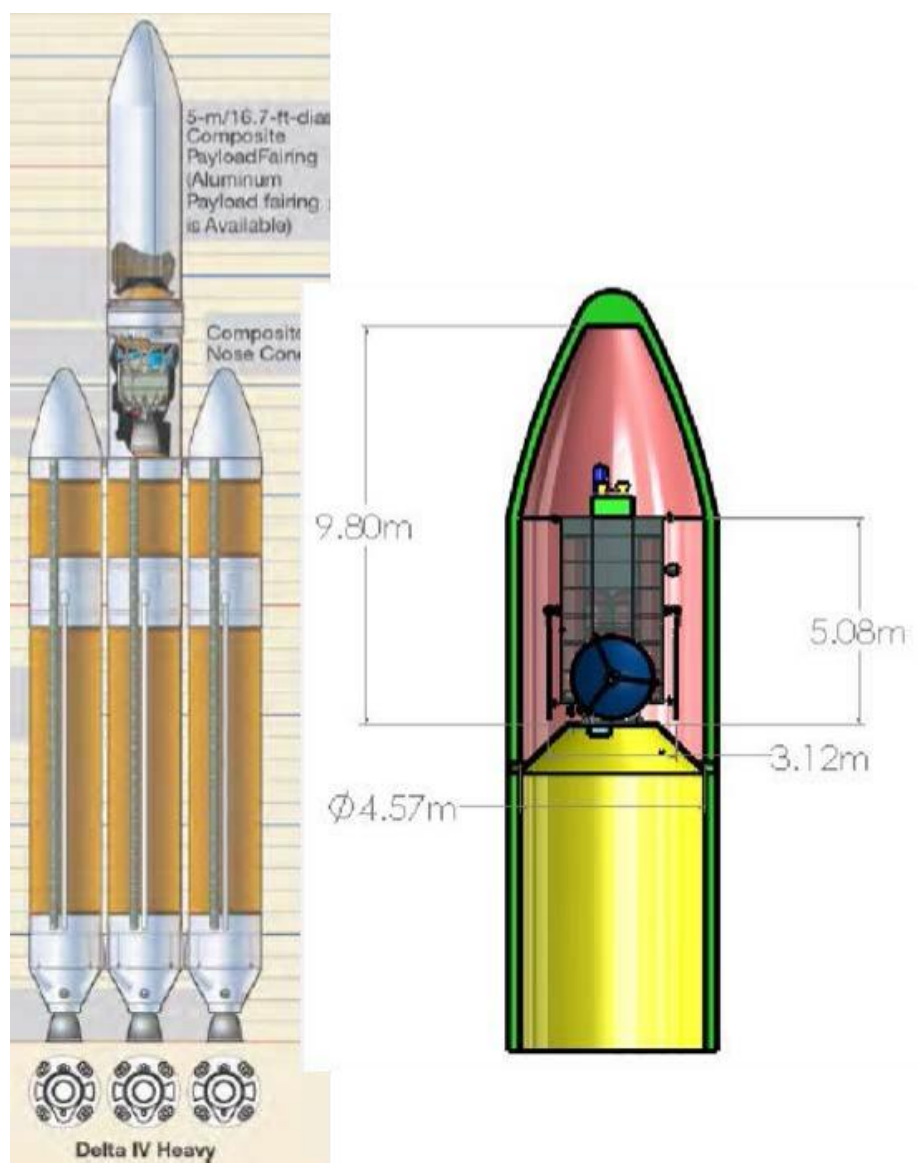

Table 2 shows the mass rack up for the entire spacecraft + payload (observatory mass $=$ total payload mass + total spacecraft wet mass). Please note that the payload carries a $0 \%$ contingency as it was used to completely maximize the mass of the launched payload to be delivered (Gross Liftoff Weight [GLOW]). Overall, at the concept Point-of-Departure level there remains just 7 kilograms of launch vehicle throw mass margin.

\section{Alternative Launch Vehicles}

Table 3 shows the options available for all other currently available launch vehicles and their launch capabilities for this point of departure mitigation target. Note that all other launch vehicles have significantly less capability of delivering a payload to the mitigation target.

Figure 11. Case Study 1 HAMMER within the Delta-IV Heavy Fairing 
Table 2. Case Study 1 Total Mass Summary (C3 of $\left.\sim 10 \mathrm{Km}^{2} / \mathrm{Sec}^{2}\right)$ Unused LV Throw Mass - $7 \mathrm{~kg}$

\begin{tabular}{|c|c|c|c|}
\hline \multicolumn{4}{|c|}{ Hammer MASS Summary } \\
\hline \multicolumn{4}{|c|}{ Payload Mass } \\
\hline Hammer Payload Dry Mass & \begin{tabular}{l|l} 
CBE &
\end{tabular} & Cont. & MEV \\
\hline Hammer Payload (Inert) & $1000.0 \mathrm{~kg}$ & $0 \%$ & $1000.0 \mathrm{~kg}$ \\
\hline Hammer Payload (Non-Inert) & $1000.0 \mathrm{~kg}$ & $0 \%$ & $1000.0 \mathrm{~kg}$ \\
\hline Hammer Payload (Balance) & $600.0 \mathrm{~kg}$ & $0 \%$ & $600.0 \mathrm{~kg}$ \\
\hline Polycam & $9.0 \mathrm{~kg}$ & $30 \%$ & $11.7 \mathrm{~kg}$ \\
\hline Radar & $100.0 \mathrm{~kg}$ & $30 \%$ & $130.0 \mathrm{~kg}$ \\
\hline Optical Camera & $5.0 \mathrm{~kg}$ & $30 \%$ & $6.5 \mathrm{~kg}$ \\
\hline Total Payload Mass & $2714.0 \mathrm{~kg}$ & $30 \%$ & $2748.2 \mathrm{~kg}$ \\
\hline \multicolumn{4}{|c|}{ Bus Dry Mass } \\
\hline Hammer Spacecraft Bus Dry Mass & CBE & Cont. & MEV \\
\hline Mechanical & $3460.2 \mathrm{~kg}$ & $30 \%$ & $4498.3 \mathrm{~kg}$ \\
\hline Thermal & $36.1 \mathrm{~kg}$ & $30 \%$ & $46.9 \mathrm{~kg}$ \\
\hline Attitude Control & $57.5 \mathrm{~kg}$ & $30 \%$ & $74.8 \mathrm{~kg}$ \\
\hline Propulsion & $142.2 \mathrm{~kg}$ & $30 \%$ & $184.9 \mathrm{~kg}$ \\
\hline Power & $224.0 \mathrm{~kg}$ & $30 \%$ & $291.2 \mathrm{~kg}$ \\
\hline Avionics (C\&DH) & $91.2 \mathrm{~kg}$ & $30 \%$ & $118.6 \mathrm{~kg}$ \\
\hline Communications & $97.1 \mathrm{~kg}$ & $30 \%$ & $126.2 \mathrm{~kg}$ \\
\hline Spacecraft Bus Dry Mass Total & $4108.3 \mathrm{~kg}$ & $30 \%$ & $5340.8 \mathrm{~kg}$ \\
\hline \multicolumn{4}{|c|}{ Observatory Mass } \\
\hline HammerObservatory Mass & CBE & Cont. & MEV \\
\hline Payload Total & $2714.0 \mathrm{~kg}$ & $0 \%$ & $2748.2 \mathrm{~kg}$ \\
\hline Spacecraft Bus Dry Mass & $4108.3 \mathrm{~kg}$ & $30 \%$ & $5340.8 \mathrm{~kg}$ \\
\hline Observatory Dry Mass & $6822.3 \mathrm{~kg}$ & $19 \%$ & $8089.0 \mathrm{~kg}$ \\
\hline Propellant + Gas & $774.0 \mathrm{~kg}$ & $0 \%$ & $774.0 \mathrm{~kg}$ \\
\hline Observatory Launch Mass & $7596.3 \mathrm{~kg}$ & & $8863.0 \mathrm{~kg}$ \\
\hline \multicolumn{4}{|c|}{ Launch Vehicle Evaluation } \\
\hline LV Throw Mass Margin* (Dry Mass) \% & & & $0 \%$ \\
\hline Launch Vehicle Capability [Delta IV Heavy] & & & $8870 \mathrm{~kg}$ \\
\hline LV Throw Mass Margin* & & & $7 \mathrm{~kg}$ \\
\hline
\end{tabular}

\begin{tabular}{|c|c|}
\hline Key: & Notes: \\
\hline CBE - Current Best Estimate & \\
\hline $\begin{array}{l}\text { Cont. - Contingency } \\
\text { MEV - Maximum Expected Value }\end{array}$ & $\begin{array}{l}\text { *MDL Margin Calculation, as weighted against LV } \\
\text { capability versus launch mass. }\end{array}$ \\
\hline
\end{tabular}

Note: $30 \%$ contingency on S/C Bus; includes redundancy for Class A mission.

Table 3. Case Study 1, Launch Vehicle Options

\begin{tabular}{|c|c|c|c|c|}
\hline \multirow[t]{2}{*}{$\begin{array}{l}\text { Vehicle vs. } \\
\text { C3 of } 10 \\
\text { km2/sec2 }\end{array}$} & $\begin{array}{c}\text { Delta IV Heavy } \\
\text { [2 launch pads, Space Launch } \\
\text { Complex (SLC)-37 Eastern Test } \\
\text { Range (ETR) and SLC-6 Western } \\
\text { Test Range (WTR)] }\end{array}$ & $\begin{array}{l}\text { Atlas V } 551 \\
\text { (ETR and } \\
\text { WTR } \\
\text { (SLC-41, } \\
\text { SLC-3E) }\end{array}$ & $\begin{array}{l}\text { Falcon } 9 \\
\text { v1.1 } \\
\text { ETR and } \\
\text { WTR (SLC- } \\
\text { 40, SLC-4E) }\end{array}$ & $\begin{array}{l}\text { Ariane } 5 \text { (linear approx.) } \\
\text { (1 Launch Pad, Kourou) } \\
\text { Your Mileage May Vary }\end{array}$ \\
\hline & $8870 \mathrm{~kg}$ & $5060 \mathrm{~kg}$ & $2625 \mathrm{~kg}$ & $6700 \mathrm{~kg}$ \\
\hline
\end{tabular}




\section{Notional SPace Segment DeVElopment AND DEPLOYMENT TIMELINE (1 ${ }^{\mathrm{ST}}$ ARTICLE ONLY)}

Figure 12 shows a notional mitigation mission development and deployment timeline. Note that it takes over 64 months in order to complete the development, design, and ATLO (Assembly, Test, and Launch Operations) of the mitigation vehicle and an additional 2 months for near earth on-orbit verification prior to the departure injection burn. Additionally, 25 months of transit time is needed in order to reach the target. In total, this accounts for over 7 years lead time (89 months) for an identified PHA target.

\section{MisSion EFFECTIVENESS / MiSSION SuCCESS}

Preliminary mission mitigation effectiveness assessment was made for each of the specific subsystems used for the Case 1 study. As derived from the spacecraft system functional block diagram for this case study, each of the subsystems was modeled. See Figure 13 for the system spacecraft functional block diagram along with the root-sum-square (RSS) functional string assessment methodology. Table 4 provides the subsystem breakdown by mission mode / phase, and the reliability assessment for each of the subsystems.
Table 4. Case 1 Study Spacecraft Subsystem Reliability Including Duration and Modes

\begin{tabular}{|l|l|c|}
\cline { 2 - 3 } \multicolumn{1}{c|}{} & \multicolumn{1}{c|}{ Mode } & Reliability \\
\hline ACS & Full Mission & 0.9989 \\
\hline Avionics & Cruise (710 Days) & 0.9994 \\
\hline Avionics & Final 30 Days & 1.0000 \\
\hline Instruments & Cruise (Standby) & 0.9919 \\
\hline Instruments & Final 30 Days & 0.9966 \\
\hline Power & Full Mission & 0.9994 \\
\hline Propulsion & Full Mission & 1.0000 \\
\hline Thermal & Full Mission & 0.9987 \\
\hline Design Reliability & Full Mission & 0.9849 \\
\hline Launch & & 0.9800 \\
\hline Mission Reliability & & 0.9652 \\
\hline
\end{tabular}

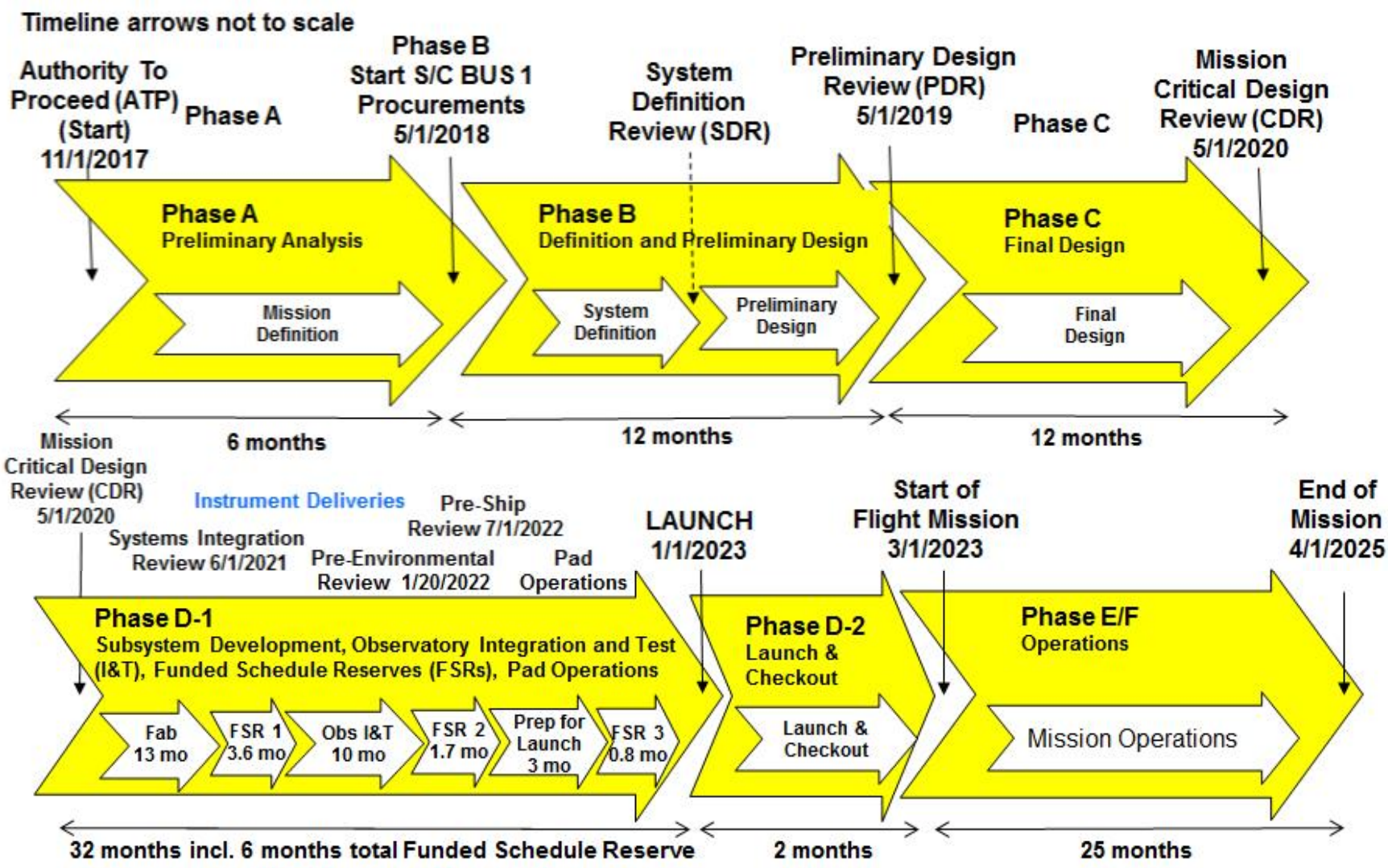

Figure 12. Case Study 1, Mitigation Mission Development and Deployment Timeline 

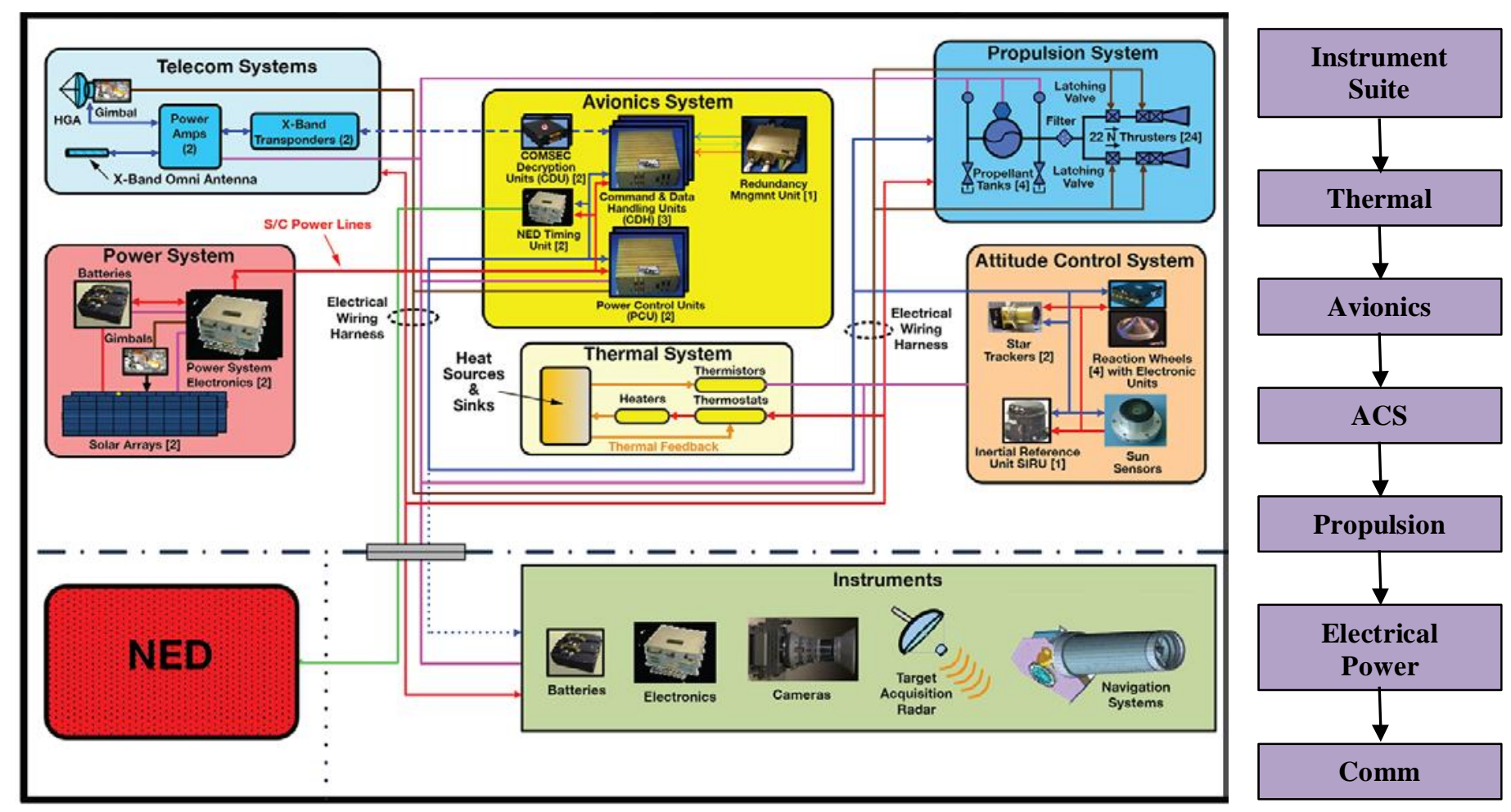

Figure 13. Preliminary Assessment of Case 1 Study Mission Reliability

Table 5 provides a multiple launch mission reliability trending assessment. $\mathrm{K}$ of $\mathrm{N}$ Mission reliability and confidence factors are depicted in the table. Key assumptions were made for both the kinetic energy/NED payload device(s) as well as software reliability. Both of these items were assumed to have a reliability factor of 1 for this initial analysis. From this table, one can see that multiple launches can achieve a high factor of confidence in delivering the payload to the PHA target. This table does not address the devaluation factors needed to account for both the software as well as the kinetic energy/NED devices. Significantly more detailed work will be needed to account for these additional subsystems as well as any future changes resulting from concept refinements and further developments.

What is noted here however, is that multiple launched missions have a significant effect in improving the overall mission confidence as denoted by each of the highlighting arrows. By employing multiple payload deliveries, one can achieve architectures or methods significantly mitigating the payload delivery system (spacecraft / launch vehicle aka transportation space segment) as an impacting factor to the overall mission reliability. It is therefore important to consider multiple launch delivery concepts in future case studies or mission level architecture or segment level concept trades.

\section{Concept of Campaign Mode}

As an extension to the MDL study Case 1 activities, joint interagency team brainstorm activities included a reference to Table 5 under the $95 \%$ column for the 1 of $5, \mathrm{k}$ of $\mathrm{n}$. Note that a confidence factor of 1 was nominally / notionally achieved, however, this involved the launch or delivery of five payloads.
Table 5. Case 1 Study Delivery of Multiple of Payloads Improving Campaign Reliability

\begin{tabular}{|l|c|c|}
\hline $\mathbf{k}$ of $\mathbf{n}$ & Mission Reliability & $\mathbf{9 5} \%$ Confidence \\
\hline $\mathbf{1}$ of $\mathbf{1}$ & 0.9652 & 0.9362 \\
\hline $\mathbf{1}$ of $\mathbf{2}$ & 0.9988 & 0.9959 \\
\hline $\mathbf{2}$ of $\mathbf{2}$ & 0.9316 & 0.8764 \\
\hline $\mathbf{1}$ of $\mathbf{3}$ & 1.0000 & 0.9997 \\
\hline $\mathbf{2}$ of $\mathbf{3}$ & 0.9964 & 0.9883 \\
\hline $\mathbf{3}$ of $\mathbf{3}$ & 0.8991 & 0.8205 \\
\hline $\mathbf{1}$ of $\mathbf{4}$ & 1.0000 & 1.0000 \\
\hline $\mathbf{2}$ of $\mathbf{4}$ & 0.9998 & 0.9990 \\
\hline $\mathbf{3}$ of $\mathbf{4}$ & 0.9931 & 0.9776 \\
\hline $\mathbf{4}$ of $\mathbf{4}$ & 0.8678 & 0.7681 \\
\hline $\mathbf{1}$ of $\mathbf{5}$ & 1.0000 & 1.0000 \\
\hline $\mathbf{2}$ of $\mathbf{5}$ & 1.0000 & 0.9999 \\
\hline $\mathbf{3}$ of $\mathbf{5}$ & 0.9996 & 0.9976 \\
\hline $\mathbf{4}$ of $\mathbf{5}$ & 0.9887 & 0.9642 \\
\hline $\mathbf{5}$ of $\mathbf{5}$ & 0.8376 & 0.7191 \\
\hline $\mathbf{1}$ of $\mathbf{6}$ & 1.0000 & 1.0000 \\
\hline $\mathbf{2}$ of $\mathbf{6}$ & 1.0000 & 1.0000 \\
\hline $\mathbf{3}$ of $\mathbf{6}$ & 1.0000 & 0.9998 \\
\hline $\mathbf{4}$ of $\mathbf{6}$ & 0.9992 & 0.9955 \\
\hline $\mathbf{5}$ of $\mathbf{6}$ & 0.9834 & 0.9486 \\
\hline $\mathbf{6}$ of $\mathbf{6}$ & 0.8084 & 0.6732 \\
\hline
\end{tabular}

This scenario includes a multiple launch delivery analysis suggesting five payloads plus two spares (see Figure 14). It is suggested that this concept may need further investigation or study along with the associated infrastructure assessments and analysis (launch facilities, launch processing operations, launch ops and support, etc.) For this concept, one may include the packaging of multiple payloads into a single launch vehicle thus reducing launch facility processing burden. 

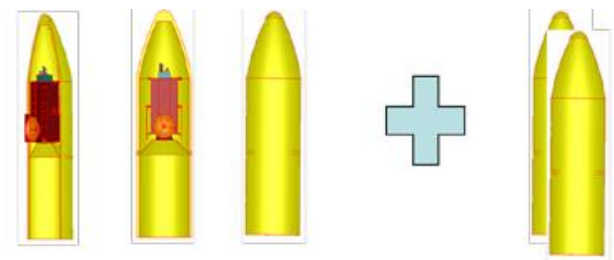

- What if from the previous multiple launcher analysis of adopting the suggestion a quantity of 5 mitigators plus 2 spares?

- This suggests the potential of $\sim 5$ launches, 5 launch vehicles, 5 launch processing facilities, and 5 launch processing teams?

- This concept and the two additions will need further exploration

- Other related / associated infrastructure questions were raised

Figure 14. Multiple Launchers

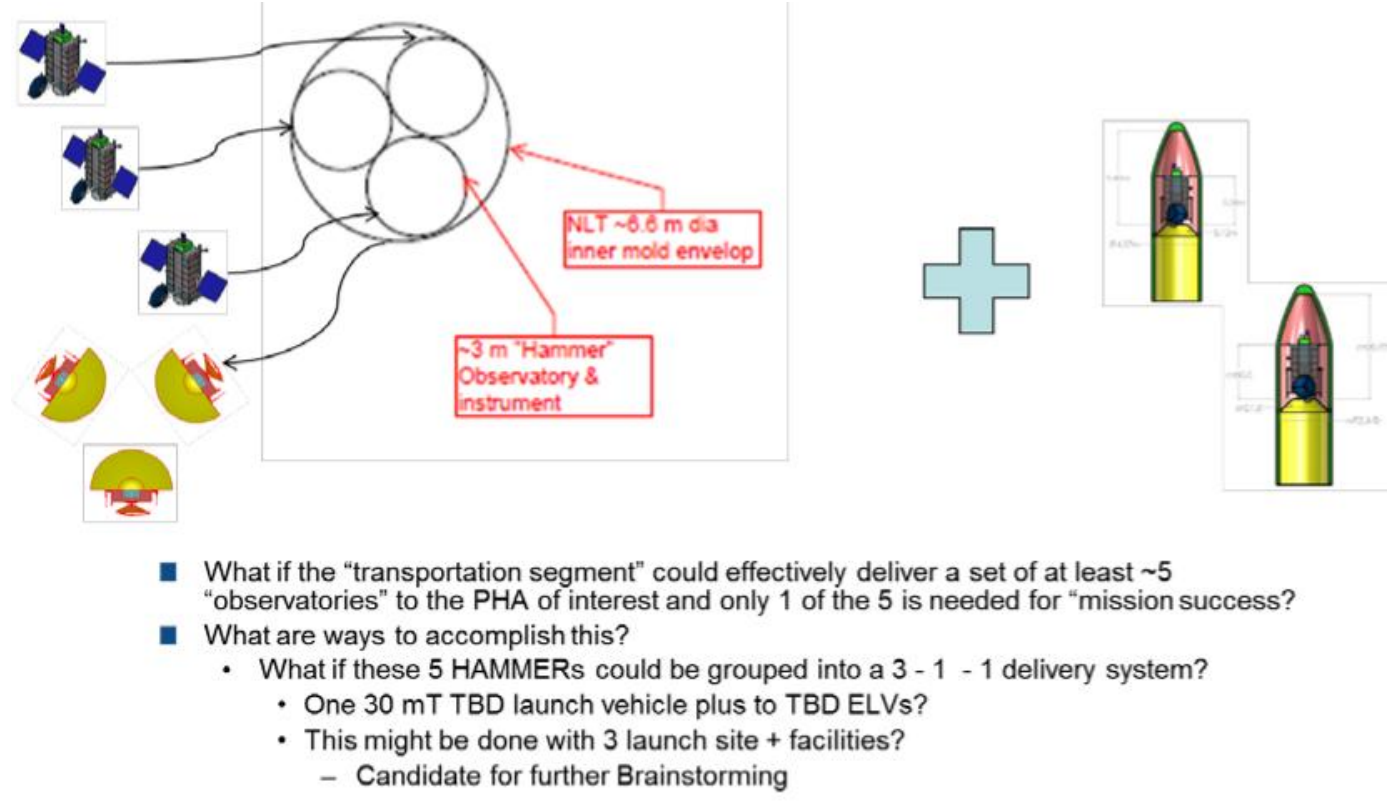

Figure 15. Concept of Packaging 3 Hammers into a Single Larger Launch Vehicle Shroud

This might be accomplished, in concept, within the Space Launch System (SLS) (see Figure 15). The SLS would be augmented by two additional Delta-IV Heavy launch vehicles. A single SLS block 1A might be capable of delivering 30 metric tons to a PHA target for mitigation (about three times the capacity of the Delta-IV Heavy). The two Delta-IV Heavy delivery systems would follow shortly thereafter as a mission reliability improvement concept providing both launch vehicle diversity as well as an additional independent payload delivery system. The total of five payloads would be delivered to the intended PHA while the goal is that only one of these is needed to achieve mitigation success. It is suggested that further case study be considered for these kinds of options.

\section{TEAM FindingS}

Preliminary study findings of the effectiveness of a KE (Kinetic Energy only) HAMMER are summarized in Table 6 through Table 10. The differences in the analysis results in these tables come from the assumed difference of one PHA characteristic, $\beta$, varied from an assumed value of 1 to an assumed value of 2.5. This $\beta$ momentum enhancement factor is coupled with the physics and physical characteristics of the PHA being mitigated. This factor is depicted in Figure 16.
The overall set of results for the various case studies is summarized in Table 6. These results include both Delta IV Heavy and SLS Block 1 launch vehicle options, either 10-year or 25-year launch lead time, single or multiple launch options, and either quantization of available spacecraft launch mass into a number of discrete HAMMER spacecraft, or utilization of all available spacecraft launch mass capability without packaging that mass into individual HAMMER spacecraft.

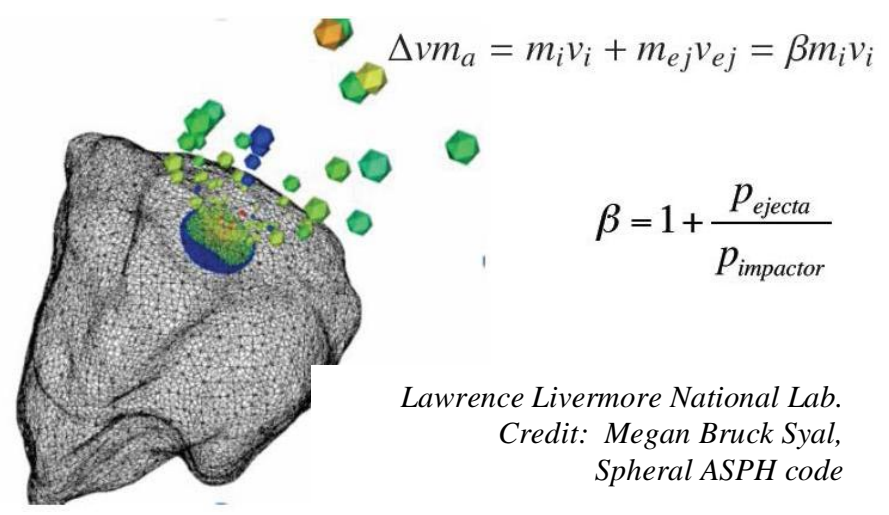

Figure 16. B, Momentum Enhancement for KI Mitigation Concepts ${ }^{[6]}$ 
Table 6. Deflection of at least $\sim 1.4$ Earth radii from Earth's surface and $\beta=1$

\begin{tabular}{|c|c|c|c|c|c|c|c|c|c|c|}
\hline $\begin{array}{l}\text { Available } \\
\text { Launch } \\
\text { Lead Time } \\
\text { (yrs) }\end{array}$ & Launch Vehicle & $\begin{array}{c}\text { Number } \\
\text { of } \\
\text { Launches }\end{array}$ & $\begin{array}{l}\text { Return } \\
\text { Impact } \\
\text { within } \\
50 \text { Years }\end{array}$ & $\begin{array}{l}\text { Used KI } \\
\text { Mass (kg) }\end{array}$ & $\begin{array}{l}\text { Total Specific } \\
\text { Energy } \\
\text { Imparted to } \\
\text { NEO }(\mathrm{J} / \mathrm{kg})\end{array}$ & $\begin{array}{c}\text { Time } \\
\text { from Defl. } \\
\text { to Earth } \\
\text { Encounter } \\
\text { (yrs) }\end{array}$ & $\begin{array}{c}\Delta v \\
\text { Imparted } \\
\text { to NEO } \\
(\mathrm{cm} / \mathrm{s})\end{array}$ & $\begin{array}{l}\text { Defl. } \\
\left(R_{E}\right)\end{array}$ & $\begin{array}{c}\text { Defl. } \\
\text { Perigee } \\
\left(R_{E}\right)\end{array}$ & $\begin{array}{c}\text { Defl. } \\
\text { Bplane } \\
\left(R_{E}\right)\end{array}$ \\
\hline 10 & Delta IV Heavy & 1 & N/A & 9072.64 & 1.051512 & 1.15 & 0.045632 & -0.168 & 0.832 & 0.085 \\
\hline 10 & $\begin{array}{l}\text { Delta IV Heavy } \\
\text { (HAMMER) }\end{array}$ & 1 & N/A & 7300 & 1.358724 & 1.07 & 0.046529 & -0.169 & 0.831 & 0.065 \\
\hline 10 & $\begin{array}{l}\text { Delta IV Heavy } \\
\text { (HAMMER) } \\
\text { Adjusted Mass } \\
\text { (max mass 7300) }\end{array}$ & 1 & N/A & 7300 & 1.358724 & 1.07 & 0.046529 & -0.169 & 0.831 & 0.065 \\
\hline 10 & SLS Block $1 \mathrm{w} / \mathrm{iCPS}$ & 1 & N/A & 3085.54 & 0.750999 & 0.55 & 0.022490 & -0.172 & 0.828 & 0.031 \\
\hline 10 & Delta IV Heavy & 75 & No & 627090.90 & 258.23607 & 8.22 & 6.266800 & 1.432 & 2.432 & 3.786 \\
\hline 10 & $\begin{array}{l}\text { Delta IV Heavy } \\
\text { (HAMMER) }\end{array}$ & 83 & No & 605900.00 & 307.56012 & 8.24 & 6.722607 & 1.435 & 2.435 & 3.789 \\
\hline 10 & $\begin{array}{l}\text { Delta IV Heavy } \\
\text { (HAMMER) } \\
\text { Adjusted Mass } \\
\text { (max mass 7300) }\end{array}$ & 83 & No & 605900.00 & 307.56012 & 8.24 & 6.722607 & 1.435 & 2.435 & 3.789 \\
\hline 10 & SLS Block $1 \mathrm{w} /$ iCPS & 29 & No & 628520.77 & 258.82489 & 8.22 & 6.281089 & 1.440 & 2.440 & 3.794 \\
\hline 25 & Delta IV Heavy & 1 & N/A & 8405.80 & 2.750032 & 22.37 & 0.074874 & -0.202 & 0.798 & 0.234 \\
\hline 25 & $\begin{array}{l}\text { Delta IV Heavy } \\
\text { (HAMMER) }\end{array}$ & 1 & N/A & 7300 & 3.882061 & 22.34 & 0.082903 & -0.213 & 0.787 & 0.244 \\
\hline 25 & $\begin{array}{l}\text { Delta IV Heavy } \\
\text { (HAMMER) } \\
\text { Adjusted Mass } \\
\text { (max mass 7300) }\end{array}$ & 1 & N/A & 7300 & 3.882061 & 22.34 & 0.082903 & -0.213 & 0.787 & 0.244 \\
\hline 25 & SLS Block $1 \mathrm{w} / \mathrm{iCPS}$ & 1 & N/A & 21811.95 & 7.135973 & 22.37 & 0.194289 & -0.213 & -0.787 & 0.607 \\
\hline 25 & Delta IV Heavy & 16 & No & 134491.38 & 43.997952 & 22.37 & 1.197949 & 1.384 & 2.384 & 3.733 \\
\hline 25 & $\begin{array}{l}\text { Delta IV Heavy } \\
\text { (HAMMER) }\end{array}$ & 17 & No & 124100.00 & 65.995730 & 22.34 & 1.409349 & 1.444 & 2.444 & 3.799 \\
\hline 25 & $\begin{array}{l}\text { Delta IV Heavy } \\
\text { (HAMMER) } \\
\text { Adjusted Mass } \\
\text { (max mass 7300) }\end{array}$ & 17 & No & 124100.00 & 65.995730 & 22.34 & 1.409349 & 1.444 & 2.444 & 3.799 \\
\hline 25 & SLS Block $1 \mathrm{w} / \mathrm{iCPS}$ & 6 & No & 130870.07 & 42.813265 & 22.37 & 1.165693 & 1.294 & 2.294 & 3.632 \\
\hline
\end{tabular}

The results in Table 6 show that, with an assumed $\beta$ of 1 , a maximum launch lead time of 25 years, and a requirement to achieve a deflection of at least $\sim 1.4$ Earth radii, neither the Delta IV Heavy nor the SLS Block $1 b$ is able to deflect Bennu with a single launch. Furthermore, the number of launches required is extremely large, ranging from 29 to 83 for the 10year launch lead time cases. Somewhat fewer launches are required for the 25-year launch lead time cases, in which the required number of launches is approximately 17 for the Delta IV Heavy or 6 for the SLS Block 1b. An additional concern is that the specific energy imparted to the asteroid is high $(\sim 250-300 \mathrm{~J} / \mathrm{kg})$ for the many-launch 10-year launch lead time cases that achieve $\sim 1.4$ Earth radii deflection. For reference, it is possible that the asteroid could be undesirably disrupted at deflection specific energy levels of $\sim 100 \mathrm{~J} / \mathrm{kg}$, although this is currently an area that requires further research.

Note that the deflection perigee values achieved for the successful cases in Table 6 are on the order of $\sim 2.3-2.5$ Earth radii. It may be that a minimally successful asteroid deflection only requires a deflection perigee altitude on the order of $\sim 0.25$ Earth radii (to essentially just barely miss the Earth), corresponding to a deflection perigee radius of $\sim 1.25$ Earth radii. Thus, the results in Table 6 may be considered to be minimally robust, while a $\sim 0.25$ Earth radii deflection perigee results set could be considered minimally functional. To understand the reduction in launch costs associated with relaxing the deflection requirement to a deflection perigee of $\sim 0.25$ Earth radii, the study was repeated with that setting, and the results are summarized in Table 7.

Note that only requiring a $\sim 1.25$ Earth radii deflection perigee radius results in only requiring deflection values on the order of $\sim 0.3$ Earth radii, much smaller than the $\sim 1.4$ Earth radii deflection required in the first results set. The number of launches required for the 10-year launch lead time cases is still extremely high, ranging from 19 to 53 launches. The number of launches required in the 25-year cases are also proportionately reduced, but still formidable at 11 Delta IV Heavy launches or 4 SLS Block 1b launches. 
We next consider the effects of $\beta$ on the results. As noted previously, $\beta$ will linearly scale the magnitude of the $\Delta v$ vector imparted to the asteroid by the kinetic impactor(s). We return to the case of requiring a deflection of $\sim 1.4$ Earth radii (which we may, perhaps, consider minimally robust) and reassess performance with a $\beta$ of 2.5 (rather than the original value of $\beta=1$ ). The results are presented in Table 8 .

Note that changing from $\beta=1$ to $\beta=2.5$ has a nearly linear (inverse) effect on the required number of launch vehicles, modulated by the fact that we model an integer number of launches (i.e., we cannot, of course, have fractional launches). This is a significant effect, and so we are motivated to seek an improved understanding of $\beta$. That said, even with $\beta>1$ we would need to deploy tens of metric tons worth of payload in order to just barely deflect Bennu (or an asteroid of similar size/mass on a similar orbit to Bennu's).

From the foregoing results, we find a HAMMER spacecraft in kinetic impactor mode is not an adequate solution for deflecting Bennu (or similar / more challenging near-Earth objects [NEOs]). This raises the question of: for what size NEO can a single HAMMER in kinetic impactor mode produce an adequate deflection? Understanding the capability of a single kinetic impactor HAMMER is important, because we want a system that is fully capable of robustly achieving the threshold deflection mission with a single spacecraft. That allows us to then deploy a campaign of several such spacecraft for mission robustness through redundancy. By contrast, a deflection mission that depends on the success of several spacecraft is much less reliable.

Table 7. Deflection of at least $\sim 0.25$ Earth radii from Earth's surface and $\beta=1$

\begin{tabular}{|c|c|c|c|c|c|c|c|c|c|c|}
\hline $\begin{array}{l}\text { Available } \\
\text { Launch } \\
\text { Lead Time } \\
\text { (yrs) }\end{array}$ & Launch Vehicle & $\begin{array}{c}\text { Number } \\
\text { of } \\
\text { Launches }\end{array}$ & $\begin{array}{l}\text { Return } \\
\text { Impact } \\
\text { within } \\
50 \text { Years }\end{array}$ & $\begin{array}{l}\text { Used KI } \\
\text { Mass (kg) }\end{array}$ & $\begin{array}{l}\text { Total Specific } \\
\text { Energy } \\
\text { Imparted to } \\
\text { NEO }(\mathrm{J} / \mathrm{kg})\end{array}$ & $\begin{array}{l}\text { Time from } \\
\text { Defl. to } \\
\text { Earth } \\
\text { Encounter } \\
\text { (yrs) }\end{array}$ & $\begin{array}{c}\Delta v \\
\text { Imparted } \\
\text { to NEO } \\
(\mathrm{cm} / \mathrm{s})\end{array}$ & $\begin{array}{l}\text { Defl. } \\
\left(R_{E}\right)\end{array}$ & $\begin{array}{l}\text { Defl. } \\
\text { Perigee } \\
\left(R_{E}\right)\end{array}$ & $\begin{array}{c}\text { Defl. } \\
\text { Bplane } \\
\left(\boldsymbol{R}_{E}\right)\end{array}$ \\
\hline 10 & Delta IV Heavy & 1 & $N / A$ & 9072.64 & 1.051512 & 1.15 & 0.045632 & -0.168 & 0.832 & 0.085 \\
\hline 10 & $\begin{array}{l}\text { Delta IV Heavy } \\
\text { (HAMMER) }\end{array}$ & 1 & $\mathrm{~N} / \mathrm{A}$ & 7300 & 1.358724 & 1.07 & 0.046529 & -0.169 & 0.831 & 0.065 \\
\hline 10 & $\begin{array}{l}\text { Delta IV Heavy } \\
\text { (HAMMER) } \\
\text { Adjusted Mass } \\
\text { (max mass } 7300 \text { ) }\end{array}$ & 1 & N/A & 7300 & 1.358724 & 1.07 & 0.046529 & -0.169 & 0.831 & 0.065 \\
\hline 10 & SLS Block $1 \mathrm{w} / \mathrm{iCPS}$ & 1 & N/A & 3085.54 & 0.750999 & 0.55 & 0.022490 & -0.172 & 0.828 & 0.031 \\
\hline 10 & Delta IV Heavy & 48 & No & 401338.2 & 165.271083 & 8.22 & 4.010763 & 0.248 & 1.248 & 2.422 \\
\hline 10 & $\begin{array}{l}\text { Delta IV Heavy } \\
\text { (HAMMER) }\end{array}$ & 53 & No & 386900.0 & 196.392874 & 8.24 & 4.292750 & 0.246 & 1.246 & 2.418 \\
\hline 10 & $\begin{array}{l}\text { Delta IV Heavy } \\
\text { (HAMMER) } \\
\text { Adjusted Mass } \\
\text { (max mass 7300) }\end{array}$ & 53 & No & 386900.0 & 196.392874 & 8.24 & 4.292750 & 0.246 & 1.246 & 2.418 \\
\hline 10 & SLS Block $1 \mathrm{w} / \mathrm{iCPS}$ & 19 & No & 411789.5 & 169.574927 & 8.22 & 4.115207 & 0.300 & 1.300 & 2.485 \\
\hline 25 & Delta IV Heavy & 1 & $\mathrm{~N} / \mathrm{A}$ & 8405.80 & 2.750032 & 22.37 & 0.074874 & -0.202 & 0.798 & 0.234 \\
\hline 25 & $\begin{array}{l}\text { Delta IV Heavy } \\
\text { (HAMMER) }\end{array}$ & 1 & $N / A$ & 7300 & 3.882061 & 22.34 & 0.082903 & -0.213 & 0.787 & 0.244 \\
\hline 25 & $\begin{array}{l}\text { Delta IV Heavy } \\
\text { (HAMMER) } \\
\text { Adjusted Mass } \\
\text { (max mass } 7300 \text { ) }\end{array}$ & 1 & $\mathrm{~N} / \mathrm{A}$ & 7300 & 3.882061 & 22.34 & 0.082903 & -0.213 & 0.787 & 0.244 \\
\hline 25 & SLS Block $1 \mathrm{w} / \mathrm{iCPS}$ & 1 & N/A & 21811.95 & 7.135973 & 22.37 & 0.194289 & -0.213 & -0.787 & 0.607 \\
\hline 25 & Delta IV Heavy & 10 & No & 92463.79 & 30.250348 & 22.37 & 0.823618 & 0.381 & 1.381 & 2.575 \\
\hline 25 & $\begin{array}{l}\text { Delta IV Heavy } \\
\text { (HAMMER) }\end{array}$ & 11 & No & 80300.00 & 42.702672 & 22.34 & 0.911927 & 0.292 & 1.292 & 2.466 \\
\hline 25 & $\begin{array}{l}\text { Delta IV Heavy } \\
\text { (HAMMER) } \\
\text { Adjusted Mass } \\
\text { (max mass } 7300 \text { ) }\end{array}$ & 11 & No & 80300.00 & 42.702672 & 22.34 & 0.911927 & 0.292 & 1.292 & 2.466 \\
\hline 25 & SLS Block $1 \mathrm{w} / \mathrm{iCPS}$ & 4 & No & 87247.81 & 28.543894 & 22.37 & 0.777157 & 0.264 & 1.264 & 2.430 \\
\hline
\end{tabular}


Table 8. Deflection of at least $\sim$ 1.4 Earth radii from Earth's surface and $\beta=2.5$

\begin{tabular}{|c|c|c|c|c|c|c|c|c|c|c|}
\hline $\begin{array}{l}\text { Available } \\
\text { Launch } \\
\text { Lead Time } \\
\text { (yrs) }\end{array}$ & Launch Vehicle & $\begin{array}{c}\text { Number } \\
\text { of } \\
\text { Launches }\end{array}$ & $\begin{array}{l}\text { Return } \\
\text { Impact } \\
\text { within } \\
50 \text { Years }\end{array}$ & $\begin{array}{l}\text { Used KI } \\
\text { Mass (kg) }\end{array}$ & $\begin{array}{c}\text { Total } \\
\text { Specific } \\
\text { Energy } \\
\text { Imparted } \\
\text { to NEO } \\
(\mathrm{J} / \mathrm{kg})\end{array}$ & $\begin{array}{l}\text { Time from } \\
\text { Deflection } \\
\text { to Earth } \\
\text { Encounter } \\
\text { (yrs) }\end{array}$ & $\begin{array}{c}\Delta v \\
\text { Imparted } \\
\text { to NEO } \\
(\mathrm{cm} / \mathrm{s})\end{array}$ & $\begin{array}{l}\text { Defl. } \\
\left(\boldsymbol{R}_{E}\right)\end{array}$ & $\begin{array}{c}\text { Defl. } \\
\text { Perigee } \\
\left(R_{E}\right)\end{array}$ & $\begin{array}{c}\text { Defl. } \\
\text { Bplane } \\
\left(R_{E}\right)\end{array}$ \\
\hline 10 & Delta IV Heavy & 1 & $\mathrm{~N} / \mathrm{A}$ & 9045.11 & 2.203519 & 4.71 & 0.16489 & -0.165 & 0.835 & 0.139 \\
\hline 10 & $\begin{array}{l}\text { Delta IV Heavy } \\
\text { (HAMMER) }\end{array}$ & 1 & N/A & 7300 & 1.223178 & 0.06 & 0.11037 & -0.172 & 0.828 & 0.017 \\
\hline 10 & $\begin{array}{l}\text { Delta IV Heavy } \\
\text { (HAMMER) } \\
\text { Adjusted Mass } \\
\text { (max mass 7300) }\end{array}$ & 1 & $\mathrm{~N} / \mathrm{A}$ & 7300 & 1.223178 & 0.06 & 0.11037 & -0.172 & 0.828 & 0.017 \\
\hline 10 & SLS Block $1 \mathrm{w} / \mathrm{iCPS}$ & 1 & N/A & 13507.25 & 9.752915 & 2.44 & 0.42392 & -0.164 & 0.836 & 0.153 \\
\hline 10 & Delta IV Heavy & 30 & No & 250836.36 & 103.2944 & 8.22 & 6.26683 & 1.432 & 2.432 & 3.786 \\
\hline 10 & $\begin{array}{l}\text { Delta IV Heavy } \\
\text { (HAMMER) }\end{array}$ & 34 & No & 248200 & 125.9879 & 8.24 & 6.88461 & 1.519 & 2.519 & 3.880 \\
\hline 10 & $\begin{array}{l}\text { Delta IV Heavy } \\
\text { (HAMMER) } \\
\text { Adjusted Mass } \\
\text { (max mass 7300) }\end{array}$ & 34 & No & 248200 & 125.9879 & 8.24 & 6.88461 & 1.519 & 2.519 & 3.880 \\
\hline 10 & SLS Block $1 \mathrm{w} / \mathrm{iCPS}$ & 12 & No & 260077.56 & 107.1 & 8.22 & 6.49771 & 1.560 & 2.560 & 3.925 \\
\hline 25 & Delta IV Heavy & 1 & $\mathrm{~N} / \mathrm{A}$ & 8405.8 & 2.750032 & 22.37 & 0.18719 & -0.224 & 0.776 & 0.584 \\
\hline 25 & $\begin{array}{l}\text { Delta IV Heavy } \\
\text { (HAMMER) }\end{array}$ & 1 & $\mathrm{~N} / \mathrm{A}$ & 7300 & 3.882061 & 22.34 & 0.20726 & -0.221 & 0.779 & 0.560 \\
\hline 25 & $\begin{array}{l}\text { Delta IV Heavy } \\
\text { (HAMMER) } \\
\text { Adjusted Mass } \\
\text { (max mass 7300) }\end{array}$ & 1 & $\mathrm{~N} / \mathrm{A}$ & 7300 & 3.882061 & 22.34 & 0.20726 & -0.221 & 0.779 & 0.560 \\
\hline 25 & SLS Block $1 \mathrm{w} / \mathrm{iCPS}$ & 1 & N/A & 21811.95 & 7.135973 & 22.37 & 0.48572 & -0.191 & 0.809 & 1.517 \\
\hline 25 & Delta IV Heavy & 7 & No & 58839.98 & 19.24910 & 22.37 & 1.31026 & 1.703 & 2.703 & 4.083 \\
\hline 25 & $\begin{array}{l}\text { Delta IV Heavy } \\
\text { (HAMMER) }\end{array}$ & 7 & No & 51100.00 & 27.17471 & 22.34 & 1.45080 & 1.546 & 2.546 & 3.911 \\
\hline 25 & $\begin{array}{l}\text { Delta IV Heavy } \\
\text { (HAMMER) } \\
\text { Adjusted Mass } \\
\text { (max mass 7300) }\end{array}$ & 7 & No & 51100.00 & 27.17471 & 22.34 & 1.45080 & 1.546 & 2.546 & 3.911 \\
\hline 25 & SLS Block $1 \mathrm{w} / \mathrm{iCPS}$ & 3 & No & 65435.04 & 21.40663 & 22.37 & 1.45712 & 2.126 & 3.216 & 4.540 \\
\hline
\end{tabular}

For the case of Bennu, we find that, with a 10-year launch lead time and $\beta=1$, a single HAMMER in kinetic impactor mode can adequately deflect an NEO up to $123.8 \mathrm{~m}$ in diameter by $\sim 1.4$ Earth radii, or deflect an NEO up to $143.62 \mathrm{~m}$ in diameter by $\sim 0.25$ Earth radii. Note that both cases assume an asteroid bulk density of $1 \mathrm{~g} / \mathrm{cm}^{3}$ and Bennu's orbit. This is important to keep in mind, because the answer will vary depending on NEO orbit, bulk density, launch lead time, warning time (which, as noted previously, is not the same as launch lead time), and other factors.

To quantify some of the variability in the size of NEO that can be dealt with via a single HAMMER, we hold the orbit constant at Bennu's orbit, and then vary the asteroid bulk density, $\beta$, and launch lead time. For each combination of those three parameters, we use our algorithms to compute the largest size asteroid that a single HAMMER spacecraft could deflect 1.4 Earth radii from Earth's surface. These results are presented in Table 9. Similar results are presented in Table 10 for deflection of at least 0.25 Earth radii.
Table 9. Effects of Density and $\beta$ on HAMMER performance, when deflection of at least 1.4 Earth radii from Earth's surface is required

\begin{tabular}{c|c|c|c|c|c|c|}
\hline $\begin{array}{c}\text { Available } \\
\text { Launch } \\
\text { Lead } \\
\text { Time } \\
\text { (yrs) }\end{array}$ & $\beta$ & $\begin{array}{c}\text { Asteroid } \\
\text { Density } \\
\left(\mathrm{g} / \mathrm{cm}^{\wedge} \mathbf{3}\right)\end{array}$ & $\begin{array}{c}\text { Diameter } \\
(\mathbf{m})\end{array}$ & $\begin{array}{c}\text { Deflection } \\
\left(\boldsymbol{R}_{\boldsymbol{E}}\right)\end{array}$ & $\begin{array}{c}\text { Specific } \\
\text { Energy } \\
(\mathbf{J} / \mathbf{k g})\end{array}$ & $\begin{array}{c}\text { Escape } \\
\text { velocity } \\
\text { fraction } \\
\left(\frac{\Delta \mathbf{v}}{v_{\text {esp }}}\right)\end{array}$ \\
\hline 10 & 1 & 1 & 123.8 & 1.436 & 307.587357 & 1.452552 \\
10 & 1 & 2.6 & 90.03 & 1.436 & 307.606364 & 1.238811 \\
10 & 2.5 & 1 & 168.02 & 1.436 & 123.040326 & 1.070316 \\
\hline 10 & 2.5 & 2.6 & 122.19 & 1.436 & 123.041062 & 0.912753 \\
\hline 25 & 1 & 1 & 210.028 & 1.444 & 65.995738 & 0.179480 \\
25 & 1 & 2.6 & 152.74 & 1.456 & 65.995028 & 0.153056 \\
25 & 2.5 & 1 & 285.052 & 1.456 & 26.397977 & 0.132241 \\
\hline 25 & 2.5 & 2.6 & 207.300 & 1.456 & 26.398039 & 0.112773 \\
\hline
\end{tabular}


Table 10. Effects of Density and $\beta$ on HAMMER performance, when deflection of at least 0.25 Earth radii from Earth's surface is required

\begin{tabular}{c|c|c|c|c|c|c}
$\begin{array}{c}\text { Available } \\
\text { Launch } \\
\text { Lead Time } \\
\text { (yrs) }\end{array}$ & $\beta$ & $\begin{array}{c}\text { Asteroid } \\
\text { Density } \\
\left(\mathrm{g} / \mathrm{cm}^{\wedge} 3\right)\end{array}$ & $\begin{array}{c}\text { Diameter } \\
(\mathrm{m})\end{array}$ & $\begin{array}{c}\text { Deflection } \\
\left(\boldsymbol{R}_{E}\right)\end{array}$ & $\begin{array}{c}\text { Specific } \\
\text { Energy } \\
(\mathrm{J} / \mathrm{kg})\end{array}$ & $\begin{array}{c}\text { Escape } \\
\text { velocity } \\
\text { fraction } \\
\left(\frac{\Delta v}{v_{\text {esp }}}\right)\end{array}$ \\
\hline 10 & 1 & 1 & 143.62 & 0.252 & 197.008810 & 0.801965 \\
10 & 1 & 2.6 & 104.4456 & 0.252 & 197.009251 & 0.683903 \\
10 & 2.5 & 1 & 194.922 & 0.252 & 78.803923 & 0.590899 \\
10 & 2.5 & 2.6 & 141.75 & 0.252 & 78.811186 & 0.503969 \\
\hline 25 & 1 & 1 & 244.6 & 0.251 & 41.780494 & 0.097566 \\
25 & 1 & 2.6 & 177.881 & 0.251 & 41.781198 & 0.083204 \\
25 & 2.5 & 1 & 331.9733 & 0.249 & 16.712194 & 0.071887 \\
25 & 2.5 & 2.6 & 241.123 & 0.256 & 16.774658 & 0.061610 \\
\hline
\end{tabular}

We observe in the foregoing results that there is an apparent scaling relationship that may be exploited to predict asteroid deflection performance for a particular mission scenario without the need to execute the trajectory grid calculations. This allows us to predict the total spacecraft mass required to deflect a given asteroid mass by a certain amount, provided that we already know how much spacecraft mass is required to impart that amount of deflection to an asteroid of some other mass. We begin with the equivalency, following from linear momentum conservation, given by

$$
\beta_{1}\left(\frac{\bar{m}_{1}}{M_{1}+\bar{m}_{1}}\right)=\beta_{2}\left(\frac{\bar{m}_{2}}{M_{2}+\bar{m}_{2}}\right)
$$

where $M_{1}$ is asteroid mass, $\beta_{1}$ is the momentum enhancement parameter used in the calculation of the asteroid's deflection, and $\bar{m}_{1}$ is the total spacecraft mass used to deflect the asteroid. Those same parameters subscripted "2" correspond to a different case of interest for which we seek to solve for one of the three parameters given the other two. Note that, for a multiple launch scenario, the total spacecraft mass is simply the sum of the masses of the individual spacecraft used to impact the asteroid, given by

$$
\bar{m}_{1}=\sum_{i=1}^{N_{1}} m_{1_{i}}
$$

where $N_{1}$ is the number of launches and $m_{1_{i}}$ is the mass of the $i^{\text {th }}$ spacecraft. If the mass of each of the $N$ spacecraft is the same, then Eq. (2) reduces to

$$
\bar{m}_{1}=N_{1} m_{1}
$$

We apply these relationships by manipulating Eq. (1) to yield a scale factor, $S_{2}$, given by

$$
\begin{gathered}
S_{2}=\left(\left(\frac{\bar{m}_{2} \beta_{2}}{\bar{m}_{1} \beta_{1} \rho_{2} V_{\text {unit }_{2}}}\right)\left(\rho_{1} S_{1}^{3} V_{\text {unit }_{1}}+\bar{m}_{1}\right)\right. \\
\left.-\frac{\bar{m}_{2}}{\rho_{2} V_{\text {unit }}}\right)^{\frac{1}{3}}
\end{gathered}
$$

where $M_{1}=\rho_{1} V_{1}=\rho_{1} S_{1}^{3} V_{\text {unit }}, \rho$ is the asteroid's density, $S$ is the scale factor corresponding to a particular asteroid radius/diameter, and $V_{\text {unit }}$ is the volume of the object when the radius is normalized to a maximum value of of 1 (unit radius volume). If each of the two asteroids being considered has the same shape, then the unit radius volume will be equal for both bodies.

When the mass of each asteroid is much greater than the total spacecraft mass impacting the asteroid $\left(\bar{m}_{1}\right.$ and $\left.\bar{m}_{2}\right)$, and the spacecraft mass per launch is constant, then the scale factor reduces to

$$
S_{2} \approx\left(\frac{\rho_{1} \beta_{2} N_{2}}{\beta_{1} \rho_{2} N_{1}}\right)^{\frac{1}{3}} S_{1}
$$

The scale factors used for the previous tables (9 and 10) are for the diameters of each object. In addition, the known parameters are variables with the subscript " 1 ," and the input variables are $\beta_{2}, N_{2}$, and $\rho_{2}$.

A similar expression, manipulating equation (1) and assuming that each system launch vehicle has the same mass (i.e. $\bar{m}=$ $\mathrm{Nm}$ ), can be found for the number of launch vehicles required

$$
N_{2}=\frac{M_{2}}{\frac{m_{2} \beta_{2}}{N_{1} m_{1} \beta_{1}} M_{1}+\left(\frac{\beta_{2}}{\beta_{1}} m_{1}-m_{2}\right)}
$$

This equation can be further reduced when the following assumptions are made: $m_{1}=m_{2}=m$, asteroid is same shape, $M_{1} \gg N_{1} m$, and $M_{2} \gg N_{1} m$

$$
N_{2} \approx \frac{\rho_{2} \beta_{1} S_{2}^{3}}{\rho_{1} \beta_{2} S_{1}^{3}} N_{1}
$$

When investigating estimation of launch vehicles across launch vehicle types and deflections, it has been found that the number of launch vehicles can be closely predicted. This is done by taking ratios from other deflections and intercept dates. Note, the deflections in each lead time must be the same, but each lead time group can have a different deflection. See Tables 6, 7, and 8 . The relation is as follows:

$$
N_{2}\left(L T_{2}, L V_{1}\right) \approx \frac{N_{2}\left(L T_{2}, L V_{2}\right)}{N_{1}\left(L T_{1}, L V_{2}\right)} N_{1}\left(L T_{1}, L V_{1}\right)
$$

Where the LT is the lead time, LV is launch vehicle type, and $\mathrm{N}$ is the number of launch vehicles required as a function of LT and LV. An example to find the number of LVs needed to deflect the asteroid $0.25 \mathrm{RE}$ with a 25 year LT using the data in Tables 7 and 8 is as follows: $N_{1}\left(L T_{1}, L V_{1}\right)=12$ (SLS), $N_{1}\left(L T_{1}, L V_{2}\right)=30$ (Delta IV), and $N_{2}\left(L T_{2}, L V_{2}\right)=10$ (Delta 
IV). Inputting these values into equation 8 yields 4 (SLS), which is the number of Launch vehicles required for deflecting the asteroid about 0.25 Earth radii with a LT of 25 years. However, further investigations must be conducted to explore the reliability of launch vehicle estimation when intercept dates greatly vary in the same lead time.

\section{SUMMARY}

- $\quad$ The HAMMER in kinetic impactor (KI) mode is clearly not an adequate solution for deflecting Bennu (or similar / more challenging NEOs).

- Improved understanding of $\beta$ is needed, as it can linearly decrease the required number of launches for kinetic impact deflection.

- $\quad$ Based on the above, even with $\beta>1$ the physics will likely dictate deploying tens of metric tons worth of spacecraft in order to just barely alter the Bennu trajectory. This study utilized both the largest vendor available launch vehicle, the Delta IV Heavy, as well as the projected capabilities of the future NASA SLS version $1 \mathrm{~b}$. The ability to use other less capable launch vehicles is highly unlikely.

- Additionally, the ability to deliver the coordinated quantity and coordinated simultaneity of these HAMMERs would be unprecedented within the currently existing national launch system infrastructure.

- Use of international infrastructure of this magnitude was beyond this current case study.

- Removing the constraints on minimum/maximum distance to the Sun resulted in marginal improvements to deflection performance with a closest approach to the Sun of $0.4-0.6 \mathrm{AU}$.
- Removing/loosening the other constraints (Declination of the Launch Asymptote [DLA], phase angle, SunSpacecraft-Earth [SSE] angle, maximum flight time, etc.) did not lead to notable deflection performance improvements (some did lead to an increase in the number of launch opportunities).

- However, the above outcomes are particular to Bennu's orbit; the situation will vary depending on the particular NEO orbit.

- A single HAMMER in kinetic impactor mode is probably adequate to deflect a NEO $\leq 180 \mathrm{~m}$ in diameter (with bulk density of $1 \mathrm{~g} / \mathrm{cm}^{3}$ and Bennu's orbit) with a 10 -year launch lead time. This mitigation approach will vary depending on NEO orbit, bulk density, and launch lead time, and warning time (which is different than launch lead time).

- It became clear from this case study that the use of multiple HAMMERs would need to be part of the top level concept formulation and trade space along with future work and analysis into the PHA physical characteristics, payload complement within HAMMER (mass centroid detectors, terminal guidance systems, longer range detection and guidance, telemetry and communications, etc.).

- The study confirms previous reports from both the National Research Council (NRC) ${ }^{[7]}$ and NASA ${ }^{[8]}$ where the NED option is needed. Table 11 shows the concepts captured thus far beginning in 2012 with Hypervelocity Asteroid Intercept Vehicle (HAIV) as a single spacecraft fight system, the Case 1 work completed in 2015, and potential options for 2016 and beyond with modular spacecraft delivery systems using multiple launch vehicles approached in campaign concept. 
Table 11. PHA Mitigation Cases and Options being Considered

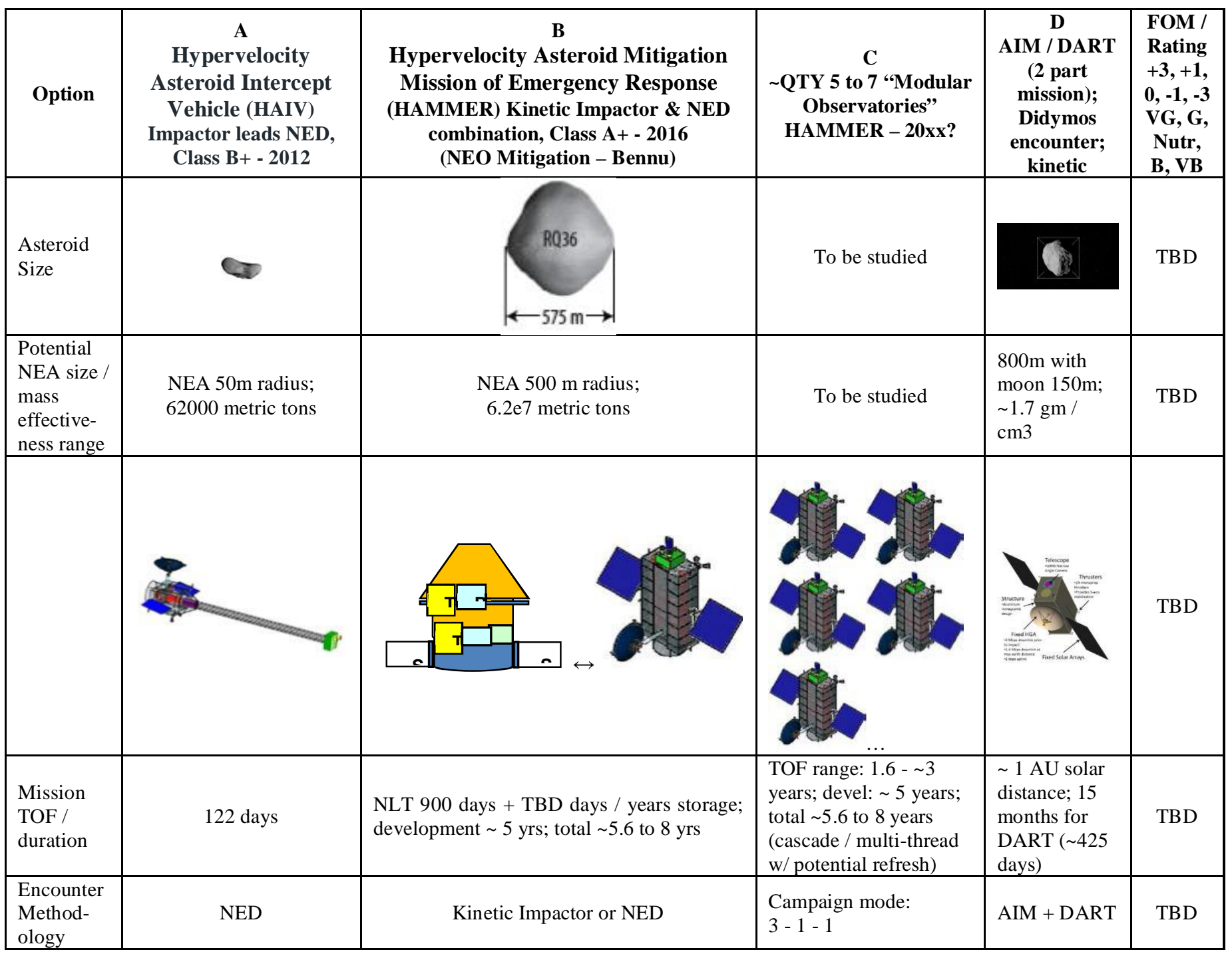

\section{ACKNOWLEDGEMENTS}

This research was supported in part by an appointment to the NASA Mission Directorate Research Participation Program. This program is administered by the Oak Ridge Institute for Science and Education through an interagency agreement between the U.S. Department of Energy and NASA.

Additional contributors to this Case Study 1: Megan Bruck Syal, Joseph Wasem, Galen R. Gisler.

\section{REFERENCES}

[1] KSC launch schedule:

https://www.kennedyspacecenter.com/events.aspx or http://www.nasa.gov/press-release/nasa-s-osiris-rex-speedstoward-asteroid-rendezvous

[2] NASA launch services: http://www.nasa.gov/directorates/heo/launch services/index. $\underline{\mathrm{html}}$
[3] Office of Safety and Mission Assurance, NASA Procedural Requirements, NPR 8705.4, Risk Classification for NASA Payloads (Updated w/change 3), Effective Date: 14 June 2004, Expiration Date: 14 June 2018.

[4] Johnson-Roth, Gail, Mission Assurance Guidelines for A-D Mission Risk Classes, Aerospace Report No. TOR-2011 (8591)-21, Prepared for: Space and Missile Systems Center, Air Force Space Command, 483 N. Aviation Blvd., El Segundo, CA 90245-2808, Contract No. FA8802-09-C0001, 3 June 2011.

[5] Alberts, David S. (David Stephen), Understanding command and control, DoD Command and Control Research Program, 2006. ISBN 1-893723-17-8

[6] Bruck Syal, Megan, Planetary Defense at LLNL: How to Protect Earth from Hazardous Asteroids, 13 January 2016, Future In-Space Operations (FISO) LLNL-PRES-659183. 
[7] Space Studies Board, National Research Council, Defending Planet Earth: Near Earth Object Surveys and Hazard Mitigation Strategies, 2010.

[8] NASA HQ Office of Program Analysis and Evaluation, Near-Earth Object Survey and Deflection Study, 2006.

[9] Barbee, B. W., Wie, B., Steiner, M., and Getzandanner, K., Conceptual Design of a Hypervelocity Asteroid Intercept Vehicle (HAIV) Flight Validation Mission, AIAA-20134544, Chapter DOI:10.2514/6.2013-4544 (2013).

[10] Dearborn, David S. P., and Ferguson, Jim M., When an Impactor is Not Enough: The Realistic Nuclear Option for Standoff Deflection, Extended Abstract 4th IAA Planetary Defense Conference - PDC 2015 13-17 April 2015, Frascati, Roma, Italy, IAA-PDC-15-03-05.

[11] Janus, P., John, Homing, Guidance (A Tutorial Report) AD-756 973, Space and Missile Systems Organization, 10 December 1964.

[12] Hawkins, M., Guo, Y., and Wie, B., Spacecraft Guidance Algorithms for Asteroid Intercept and Rendezvous Missions, International Journal of Aeronautical \& Space Science, Vol. 13 (2), pp. 154-169 (2012).

[13] Lyzhoft, J., Hawkins, M., and Wie, B., GPU-Based Optical Navigation and Terminal Guidance Simulation of a Hypervelocity Asteroid Intercept Vehicle, AIAA-2013-4966, AIAA Guidance, Navigation, and Control Conference, Boston, MA, August 19-22, 2013.

[14] Moran, Inanc and Altilar, Turgay, Three Plane Approach for 3D True Proportional Navigation, AIAA Guidance, Navigation, and Control Conference, 2005.

[15] Hawkins, Matt, Pitz, Alan, Wie, Bong, and Gil-Fernandez, Jesus, Terminal-Phase Guidance and Control Analysis of Asteroid Interceptors, AIAA Guidance, Navigation, and Control Conference, 2010.

[16] Barbee, Brent W., Wie, Bong, Steiner, Mark, Getzandanner, Kenneth, Conceptual design of a flight validation mission for a Hypervelocity Asteroid Intercept Vehicle, Acta Astronautica, Volume 106, January-February 2015, pp. 139-159, ISSN 0094-5765.

\section{BIOGRAPHY}

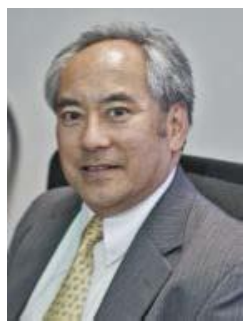

Ronald Y. Leung is currently the Exploration Systems Projects (ESP) Office Chief Engineer at NASAGoddard Space Flight Center (GSFC) where he develops architectures and advanced concepts. He has been with GSFC over 35 years and served in the NASA HQ Office of Chief Technologist and also has DoD experience. NASA projects include Orion Optical Communications formulation, Mars Architecture Team, Human
Exploration Architecture Team (MAT/HAT), Orion Crew Exploration Vehicle, and Altair Lunar Lander formulation, and TDRSS (Tracking and Data Relay Satellite System) development. His Civil / DoD experience includes: Air Traffic Control / Air Defense systems, Moscow Hotline, Navy's ELF and Army's Patriot systems. He's received several GSFC / NASA Group Achievement Awards, TDRSS Service Awards, and Westinghouse President's Quality Achievement Award. He received his B.S.E.E from the University of Maryland and M.E.A work at the George Washington University.

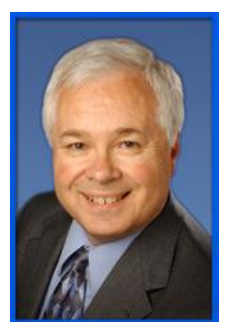

Bernard D. Seery is the Assistant Director for Advanced Concepts at NASA GSFC. He has over 37 years of domestic and international experience as a principal investigator for federal aerospace research projects and a leader of various technical organizations. Mr. Seery has an M.S. in Optical Sciences, University of Arizona, Tucson and is a graduate of the Kennedy School of Government Senior Executive Fellows Program.

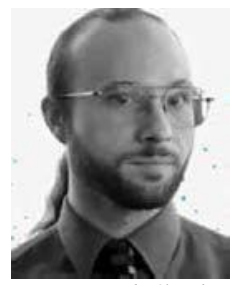

Brent W. Barbee is an Aerospace Engineer in the Navigation and Mission Design Branch at NASA GSFC; he also teaches graduate courses in the Department of Aerospace Engineering at the University of Maryland. Mr. Barbee supported flight dynamics for launch of the OSIRIS-REX asteroid sample return mission, which launched on September 8, 2016, is the technical lead for NASA's Near-Earth Object Human Space Flight Accessible Targets Study (NHATS), and conducts research on planetary defense against hazardous near-Earth objects. Mr. Barbee is a recipient of NASA's Early Career Achievement Medal and the AIAA National Capital Section 2012-2013 Hal Andrews Young Engineer/Scientist of the Year Award. He received his Bachelor and Master of Science degrees in Aerospace Engineering from the University of Texas at Austin.

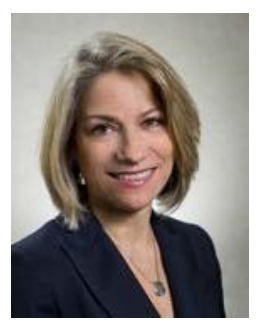

Myra Bambacus of NASA/GSFC currently serves as a Program/Project Manager in the Advanced Concepts and Formulation Office under the Flight Project Directorate. She serves as the Deputy of GSFC's Strategic Collaboration Initiative and the Project manager to the NASA/NNSA NEO Mitigation effort. Ms. Bambacus has served in a variety of leadership positions including Senior Advisor to the CIO for Cross Cutting Solutions. Ms. Bambacus's career has encompassed both the Department of Defense and NASA. She is a University of Maryland graduate of Political Science and Public Administration and a Senior Fellow in the Excellence in Government Fellows Program. 


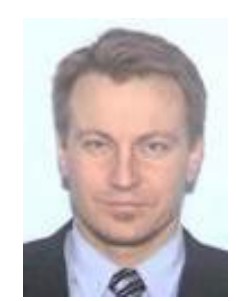

Lee Finewood is a Program Manager in the Office of Strategic Partnerships Programs at the National Nuclear Security Administration (NNSA). In this position he oversees work with other federal agencies, foreign countries, and private industry, including working level responsibilities for the Planetary Defense collaboration between NNSA and NASA. Prior to this position, he worked in defense nuclear nonproliferation and emergency operations in NNSA. Prior to joining the Department of Energy, Lee worked as a transportation engineer at Booz. Allen Hamilton. Lee completed his Masters of Science degree from the State University of New York while serving as a Fellow at the National Research Council's National Academy of Sciences.

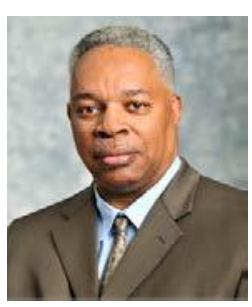

Dr. Kevin C. Greenaugh is the Assistant Deputy Administrator for Strategic Partnership Programs of NNSA. Most recently, he served as the Senior Advisor for Policy to the Administrator of NNSA. Dr. Greenaugh manages close to $\$ 2 B$ in Strategic Partnership Projects, critical to enabling nuclear deterrence, nonproliferation and counter terrorism programs in addition to enabling broader National Security missions. He is the Executive Secretary of the Mission Executive Council comprised of Under-Secretaries of four major agencies. He has over 35 years' experience working in the nuclear enterprise. Dr. Greenaugh received his Bachelor's degree in Chemistry from Mercer University, Master's in Nuclear Engineering from the University of New Mexico (Albuquerque), Master's in Public Policy from the University of New Mexico (Santa Fe), Post-Masters studies at the University of Arizona, and his doctorate in Nuclear Engineering from the University of Maryland.

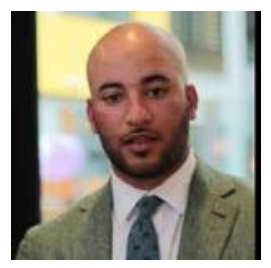

Anthony Lewis served as a Program Manager in the Office of Interagency Work at NNSA. He oversees work with other federal agencies, foreign countries, and private industry, including working level responsibilities for the Planetary Defense collaboration with NNSA and NASA. He is also the Action Officer for the Mission Executive Council. Prior to joining the DoE, Anthony worked as an engineer at Booz Allen Hamilton's Modeling, Simulation, Wargaming, and Analysis office. Anthony obtained his Bachelor of Science degree in Electrical Engineering from the University of Maryland, College Park.

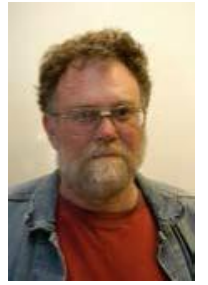

Dr. David S. P. Dearborn is a physicist at Lawrence Livermore National Laboratory (LLNL). Trained in astrophysics, he has published on multi-dimensional stellar modeling, nucleosynthesis, and astroparticle physics. He was the 1998 Selby Fellow of the Australian Academy of
Science, has won two Dudley awards for history of Astronomy. He has also been presented with several Awards of Excellence from the DoE for work on laser experiments, radar analysis, and the W87 LEP. His programmatic work has included the design and testing of both nuclear and conventional explosives. Current responsibilities include improved understanding the output and effects of nuclear weapons, as well as being an active member of the LLNL ICBM flight-test program. He has decades of research on the diversion of asteroids by nuclear explosives, and he served on a National Academy panel for asteroid mitigation. He is continuing this work today with detailed simulations demonstrating the capability of nuclear explosives to provide the required impulses to deflect asteroids. He is a graduate of UCLA (1970) and the University of Texas at Austin (1975). He has held positions at the Copernicus Institute in Warsaw, the Institute of Astronomy in Cambridge, The California Institute of Technology, and Steward Observatory in Tucson.

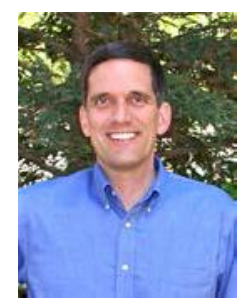

Dr. Paul Miller is Associate $A X$ Division Leader at LLNL. Research interests include high-energy-density physics; fluid dynamic mixing and turbulence; behavior of materials; atomic-scale transport processes; scientific modeling, simulation, and analysis; and asteroid threat mitigation. Dr. Miller has a Ph. D. in Applied Physics from California Institute of Technology

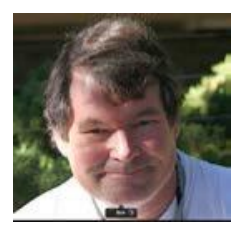

Dr. Robert P. Weaver is Fellow of the Los Alamos National Laboratory (LANL) who is currently working on the Science-Based Stockpile Stewardship (SBSS) program for the DoE. His current position is a Laboratory Fellow. During his 38-year career at Los Alamos, Dr. Weaver has received the Laboratory Distinguished Performance Award on 11 separate occasions, and several dozen DoE Awards for Excellence. He was selected by the LANL Director to be a Fellow of the Laboratory in 1999 for his sustained high-quality work on Laboratory programs. His 1977 Ph.D. thesis topic "Interstellar Bubbles" has resulted in over 2500 citations and continues to receive numerous citations after 37 years! He joined Los Alamos National Lab in 1978, after a one-year postdoctoral appointment by the National Academy of Science at NASA/GSFC. Dr. Weaver received a B.S in Astrophysics and Math from Colgate University, MS in Physics and Ph.D Astrophysics from the University of Colorado

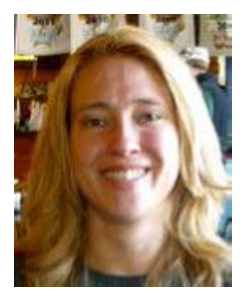

Dr. Catherine Plesko is a Research Scientist at LANL. An astrophysicist, the focus of her work is on Planetary Security, and studying asteroid impact mitigation. Dr. Plesko has a Ph.D. in Geophysics, with a Concentration in Planetary Sciences, from the University of California Santa Cruz. 